\title{
TITLE: Antigenic modulation limits the efficacy of anti-CD20 antibodies: implications for antibody selection
}

Running title: Rituximab modulates CD20 from the B-cell surface

Stephen A Beers ${ }^{1 \S}$, Ruth R French ${ }^{1 \S}$, Claude HT Chan ${ }^{1}$, Sean H Lim ${ }^{1}$, Timothy C Jarrett ${ }^{1}$, Regina Mora Vidal ${ }^{1}$, Sahan S Wijayaweera ${ }^{1}$, Sandra V Dixon ${ }^{1}$, Hyung J Kim ${ }^{1}$, Kerry L Cox $^{1}$, Jonathan P Kerr ${ }^{1}$, David A Johnston ${ }^{2}$, Peter W M Johnson ${ }^{3}$, Sjef Verbeek ${ }^{4}$, Martin J Glennie $^{1 \#}$ and Mark S Cragg ${ }^{1 \#}$

From: ${ }^{1}$ Tenovus Laboratory, Cancer Sciences Division, Southampton University School of Medicine, General Hospital, Southampton, SO16 6YD, UK. ${ }^{2}$ Biomedical Imaging Unit, Southampton University School of Medicine, General Hospital, Southampton, SO16 6YD, UK. ${ }^{3}$ Cancer Research UK Cancer Centre, Southampton University School of Medicine, General Hospital, Southampton, SO16 6YD, UK. ${ }^{4}$ Department of Human Genetics, Leiden University Medical Centre, Leiden, The Netherlands.

$\S$ These authors contributed equally to the project and should both be considered first authors. " These authors are the senior authors and contributed equally to the study. 
Address correspondence and reprint requests: Mark S Cragg, Tenovus Laboratory, Cancer Sciences Division, Southampton University School of Medicine, General Hospital, Southampton, SO16 6YD, UK (FAX: +44 (0) 2380777222 8056; e-mail: msc@soton.ac.uk)

Scientific Heading: Immunobiology 


\begin{abstract}
Rituximab, a monoclonal antibody which targets CD20 on B-cells, is now central to the treatment of a variety of malignant and autoimmune disorders. Despite this success a substantial proportion of B-cell lymphomas are unresponsive or develop resistance, hence more potent anti-CD20 mAb are continually being sought. Here we demonstrate that type II (tositumomab-like) anti-CD20 mAb are 5 times more potent than type I (rituximablike) reagents in depleting human CD20 Tg B-cells, despite both operating exclusively via activatory FcR-expressing macrophages. Much of this disparity in performance is attributable to type I mAb-mediated internalization of CD20 by B-cells leading to reduced macrophage recruitment and the degradation of CD20:mAb complexes, shortening mAb half-life. Importantly, human B cells from healthy donors, and most cases of Chronic Lymphatic Leukemia (CLL) and Mantle Cell Lymphoma, showed rapid CD20 internalization which paralleled that seen in the Tg mouse B cells, while most Follicular Lymphoma (FL) and Diffuse Large B-Cell Lymphoma (DLBCL) cells were far more resistant to CD20 loss. We postulate that differences in CD20 modulation may play a central role in determining the relative efficacy of rituximab in treating these diseases and strengthen the case for focusing on type II anti-CD20 mAb in the clinic.
\end{abstract}




\section{Introduction}

The antibody rituximab is widely used in the treatment of B-cell diseases, and many second and third generation anti-CD20 monoclonal antibodies (mAb) are currently undergoing clinical development ${ }^{1}$. Persistent lack of clarity regarding the precise mode of action for anti-CD20 mAb is reflected in the variety of approaches being taken to improve the potency of these reagents ${ }^{2}$. While it is widely accepted that $\mathrm{Fc}: \mathrm{Fc} \gamma$ receptor $(\mathrm{Fc} \gamma \mathrm{R})$ interactions are vital ${ }^{3,4}$, the importance of the two other potential effector pathways, complement-dependent cytotoxicity (CDC) and programmed cell death (PCD), is still disputed ${ }^{5}$. We have previously described two classes of anti-CD20 mAb, based upon differences in their engagement of the antigen; type I (rituximab-like) and type II (tositumomab-like). Type I mAb are able to redistribute CD20 into lipid rafts and evoke complement activation, whereas type II induce homotypic adhesion and non-apoptotic cell death ${ }^{6-8}$. Interestingly, type I and II reagents cannot be distinguished by the region of CD20 they engage, since almost all anti-CD20 mAb share small, closely overlapping epitopes which focus on an Alanine x Proline motif identified by Deans and colleagues 9,

10. It seems more likely that it is the orientation of binding and the degree of CD20 crosslinking which determine their type and nature.

The efficacy of rituximab in lymphoma therapy varies according to tumor burden ${ }^{11,12}$ and sub-type. Although FL are relatively sensitive, B-CLL and Small Lymphocytic Lymphoma (SLL) are significantly less so ${ }^{13}$, such that dose escalation with approximately 6 times more $\mathrm{mAb}$ is required for significant clinical activity ${ }^{14,} 15$. Although the second generation type I anti-CD20 mAb ofatumumab appears promising 
${ }^{16-18}$, large $(2 \mathrm{~g})$ quantities of $\mathrm{mAb}$ are being administered in these trials. The lower level of CD20 expression on CLL is put forward as a possible explanation ${ }^{19}$ although intuitively this might be expected to consume less mAb. Similarly, it has been suggested that soluble CD20 might consume rituximab in $\mathrm{CLL}^{20}$, but this result has not been confirmed and seems unlikely given the hydrophobic nature of CD20 which, with a predicted tetraspan structure, is unlikely to persist as a soluble, antigenically intact molecule. Some reports have also suggested that modulation of CD20 occurs on CLL and NHL lines but these data have been largely unconfirmed with little indication in the literature to suggest that this is an important mechanism which impedes efficacy ${ }^{21,22}$. We now show that modulation is potentially a key factor in determining the potency of CD20 mAb against certain B-cell targets and propose that type II reagents which avoid internalization are likely to be more effective drugs for deleting autoimmune and malignant B-cells in various disorders. 


\section{Material and Methods}

\section{Animals and cells}

Mice were bred and maintained in local facilities. hCD20 Tg mice have been described

previously ${ }^{1}$. Other genetically altered strains used were: $\gamma$ chain -/-, C1q -/-, C3 -/(Jax® Mice, USA), Vav-Bcl-2 Tg. hCD20 Tg x $\gamma$ chain -/- and Vav-Bcl-2 x hCD20 Tg mice were obtained by crossbreeding, with genotypes confirmed by PCR and/or flow cytometry. Animal experiments were cleared through local ethical committee and were performed under Home Office licence PPL30/1269. Human cell-lines were obtained from ECACC (Daudi, Raji, Ramos, SU-DHL-4), were a kind gift from Dr J Teeling (Granta 519) or Dr L Nolan (DOHH-2, HBL-1, RL) and were maintained in antibiotic-free media. Mouse splenic B-cells and normal human peripheral B-cells were purified by negative selection using MACS B-cell isolation kits (Miltenyi Biotec).

\section{Antibodies and reagents}

All mAb have previously been described ${ }^{1}$ except for FGM6, which is a novel type II anti-CD20 mAb constructed from patented published sequences with additional mutations. MAb were produced in either the $293 \mathrm{~F}$ Freestyle system (Invitrogen) or CHO$\mathrm{K} 1$. IgG was purified on Protein A with purity assessed by electrophoresis (Beckman EP system; Beckman) and lack of aggregation by HPLC. F(ab' $)_{2}$ fragments were produced as described previously ${ }^{23}$. Antibodies used for Western blotting were anti-CD20 (7D1)(AbDSerotec), anti-actin (Sigma) and anti-Alexa 488 (Invitrogen). Clodronate (Sigma) or PBS containing liposomes were produced as detailed by van Rooijen and 
Sanders ${ }^{24}$. The actin inhibitor Latrunculin B was from Calbiochem and azide, etoposide and dexamethasone from Sigma.

\section{Flow cytometry}

Fluorescently conjugated mAb were from BD Biosciences, AbDSerotec or made in-

house. Flow cytometry was as described previously ${ }^{25}$ with samples assessed on a FACScan, FACSCalibur or FACSCanto II with data analyzed with CellQuest Pro or FACSDiva (all BD Biosciences). To assay anti-CD20 mAb (mouse IgG2 subclass) concentrations, sera were incubated with human SU-DHL-4 cells (hCD20+), and cellbound anti-CD20 detected using FITC-labeled goat anti-mouse Fc (Jackson Immunoresearch) with reference to a standard curve. To determine surface expression of CD20 after mAb treatment in vivo or in vitro, available antigen was saturated with excess anti-CD20 mAb $(10 \mu \mathrm{g} / \mathrm{ml})$, cells washed and then surface anti-CD20 detected using RPE-labeled goat anti-mouse Fc (Jackson Immunoresearch); B-cells were then identified with APC-labeled anti-mouse CD19. FACS staining of Bcl-2 levels in hCD20 Tg B cells was performed with FITC-labeled anti-Bcl-2 (BD Biosciences) according to the manufacturer's instructions.

\section{B-cell depletion experiments}

hCD20 Tg mice received a single intravenous (i.v.) dose of $\mathrm{mAb}$ and $\mathrm{B}$ cells remaining in the blood or organs assessed by flow cytometry or immunohistochemistry (IHC) ${ }^{1}$. 
Residual B cells were plotted as percentage of B cells in mice treated with irrelevant isotype matched $\mathrm{mAb}$ (WR17) or PBS. In adoptive transfer experiments, splenocytes from hCD20 $\mathrm{Tg}$ and wild-type mice were labeled with $5 \mu \mathrm{M}$ and $0.5 \mu \mathrm{M}$ CFSE (Molecular Probes) respectively, mixed (1:1), and injected i.v. into recipients (1-3 x $10^{6} /$ mouse), followed $24 \mathrm{~h}$ later by mAb i.v.. $16 \mathrm{~h}$ later splenocytes were analyzed to determine target to non-target CFSE-labeled B cells ratio. To assess depletion of hCD20 Tg x Vav-Bcl-2 B cells, hCD20 x Vav-Bcl-2 and hCD20 Tg splenocytes were labeled with $5 \mu \mathrm{M}$ and $0.5 \mu \mathrm{M}$ CFSE, respectively, and wild-type splenocytes with $20 \mu \mathrm{M}$ PKH26 (Sigma), mixed (1:1:1), injected and treated with mAb as described above. The ratio of both target B cell populations was compared with the PKH26 labeled non-target cells.

\section{Clinical Samples}

Ethical approval for the use of clinical samples was obtained by the Southampton University Hospitals NHS Trust from the Southampton and South West Hampshire Research Ethics Committee. Informed consent was provided in accordance with the Declaration of Helsinki. Samples were released from the Human Tissue Authority licensed University of Southampton, Cancer Science Division Tissue Bank. Samples were assessed as single cell suspensions that had been isolated, Ficoll purified and cryopreserved for subsequent analysis. 


\section{Western blotting}

Western blotting was performed as described previously ${ }^{26}$. Briefly, 2.5-5 x 10 ${ }^{6}$ hCD20 Tg B cells were treated for $6 \mathrm{~h}$ in vitro with Alexa-488 mAb $(10 \mu \mathrm{g} / \mathrm{ml})$, washed and lysed in onyx buffer. Samples were then separated by SDS PAGE and proteins transferred immediately onto PVDF membrane. Membranes were blocked with 5\% non-fat dried milk, incubated with the appropriately diluted primary antibodies, washed and then incubated with horseradish peroxidase-conjugated anti-rabbit or anti-mouse $\operatorname{IgG}$ (Sigma Aldrich) and visualized by enhanced chemiluminescence (ECL, GE Healthcare) and exposure to light-sensitive film (Hyperfilm ECL, GE Healthcare).

\section{Internalization assay and Alexa-488 labeling}

MAb were labeled with Alexa-488 according to the manufacturer's instructions (Invitrogen). Samples were incubated with Alexa-488 labeled mAb $(5 \mu \mathrm{g} / \mathrm{ml})$, harvested after 2, 6 or $24 \mathrm{~h}$, washed, resuspended and incubated at $4^{\circ} \mathrm{C}$ for $30 \mathrm{~min}$ in the presence or absence of anti-Alexa-488 quenching antibody (Invitrogen). Samples were then assessed by flow cytometry. With human peripheral blood, B cells were identified by staining with RPE-labeled anti-CD19.

\section{PCR for CD20 mRNA}


Purified B cells were treated as indicated and total RNA isolated, before conversion to cDNA (Invitrogen). PCR was performed using appropriate dilutions of cDNA and primers specific for human CD20 or mouse GAPDH as a control.

\section{Phagocytosis assay}

To generate bone marrow derived macrophages, adherent cells were isolated from the femurs of C57B1/6 mice and cultured in vitro using L929 conditioned media for 5-8 days. On the day of the assay, macrophages were harvested using trypsin/EDTA (Invitrogen), resuspended in RPMI and plated into a 96-well tissue culture plate (5 × $10^{4} /$ well), and incubated for $2-4 \mathrm{~h}$ at $37^{\circ} \mathrm{C}$. Target B cells were prepared from spleens of hCD20 $\mathrm{Tg}$ mice and incubated for $16 \mathrm{~h}$ in the presence or absence of anti-CD20 mAb $(10 \mu \mathrm{g} / \mathrm{mL})$ to allow any modulation to take place, and then labeled with $5 \mu \mathrm{M}$ CFSE. The cells which had not been treated with $\mathrm{mAb}$ were then labeled with anti-CD20 mAb for $30 \mathrm{~min}$ at room temperature to obtain the maximum level of surface binding. The B cells were then added to the macrophages at a ratio of $5: 1$, the plates incubated for $30 \mathrm{~min}$ at $37^{\circ} \mathrm{C}$ then APC-anti-F4/80 antibody (AbDSerotec) added to distinguish the macrophages. Cells were harvested and analyzed by flow cytometry. The percentage of cells that stained double positive for CFSE and APC-anti-F480, which includes macrophages with both surface bound and internalized B-cells, was determined as a measure of phagocytic potential. For qualitative evidence of phagocytosis macrophages were seeded into chambers slides (ibidi) with CFSE-labeled targets prepared as above. Following removal of unbound targets, slides were then imaged by confocal microscopy using LAS-AF v2 software on a TCS-SP5 laser scanning confocal microscope (Leica Microsystems). 


\section{Fluorescence and Confocal Microscopy}

\section{In vitro modulation}

Cells were incubated with Alexa-488 conjugated anti-CD20 mAb as required, and then $50 \mathrm{nM}$ Lysotracker Red DND-99 or $5 \mu \mathrm{g} / \mathrm{ml}$ Alexa-647 conjugated transferrin (both Invitrogen) were used for lysosome and endosome analysis respectively. Cells were then transferred onto slides and images captured immediately using LAS-AF v2 software on a TCS-SP5 laser scanning confocal microscope (Leica Microsystems).

\section{In vivo modulation}

Mice were treated with Alexa-488 conjugated anti-CD20 (100 $\mu$ g i.v.) for $24 \mathrm{~h}$, then spleens were removed, paraformaldehyde fixed sections counterstained with TOPRO-3 (Invitrogen), and imaged as above.

\section{Statistical analysis}

To compare differences between the experimental groups, a two-tailed t-test was performed using GraphPadPrism software. 


\section{Results}

\section{Fc $\gamma$ Receptor dependent depletion in human CD20 transgenic (hCD20 Tg) mice}

Type II (tositumomab-like) anti-CD20 mAb demonstrate significantly prolonged clearance of circulating B cells in congenic hCD20 Tg models when compared with their type I (rituximab-like) counterparts $\left({ }^{1,27}\right.$ and Fig 1a). As a result of this enhanced potency, a single dose of $250 \mu \mathrm{g}$ of type II mAb typically cleared circulating B cells for 60 days, compared with 20-30 days for type I reagents. Using an in vivo transfer model we also demonstrated enhanced splenic B-cell depletion by type II mAb (Fig. 1b). This depletion was dose dependent (Fig. 1c) and when comparing IgG2a isotype matched versions of rituximab (Rit $\mathrm{m} 2 \mathrm{a}$ ) and tositumomab, the latter was approximately 5 times more potent. Type I mAb have been variously proposed to engage complement ${ }^{28,29}$ and apoptotic cell death mechanisms ${ }^{30,31}$. To examine these different effector mechanisms, a series of transfer experiments was performed either with recipient mice lacking key effector molecules or with transferred cells from modified donors (Fig. 1d). In C1q -/and C3-/- mice, the degree of B-cell depletion was equal to that in WT mice, suggesting no requirement for complement in this model $^{1}$. When apoptosis-resistant (see Supplementary Fig. 1 and ${ }^{32}$ ) double transgenic hCD20 x Vav Bcl-2 target cells were transferred, they were no less susceptible to depletion than normal hCD20 Tg targets with either type I or II $\mathrm{mAb}$, indicating that induction of apoptosis is not a key effector mechanism in this model. In contrast, when engagement of mAb through Fc $\gamma \mathrm{R}$ was abrogated, either by transfer into $\gamma$-chain -/- mice or by utilizing $\mathrm{F}\left(\mathrm{ab}{ }^{\prime}\right)_{2}$ fragments, B-cell depletion was completely curtailed (Fig. 1d, Supplementary Fig. 2) supporting a vital role 
for Fc $\gamma \mathrm{R}$ dependent effector mechanisms ${ }^{3,33,34}$. Importantly, lack of activity with type II $\mathrm{mAb}$ in both Fc $\gamma \mathrm{R}$-blunted models also indicates the lack of a role for the $\mathrm{Fc}$ independent non-apoptotic lysosome mediated cell death we have previously described ${ }^{6,8,35}$. Although seemingly at odds, these results can be reconciled by considering the different nature of the models used. Fc independent cell death can be demonstrated in a range of malignant B cells, with both cell lines and primary samples and, we would postulate, could be an important mechanism in this setting. However, we and others ${ }^{36}$ have been unable to demonstrate potent directly induced cell death in normal $\mathrm{B}$ cells in the absence of a mitogenic signal whether in human cells or hCD20 $\mathrm{Tg}$ mouse cells ex vivo or in vivo suggesting that this form of mAb-induced cell death may depend on cell cycling or prior triggering of the BCR. In this sense, the current observations regarding the depletion of normal B cells may have more relevance to the ever increasing use of anti-CD20 mAb in autoimmune conditions.

Having demonstrated the importance of Fc $\gamma \mathrm{R}$ mechanisms in this model, we wanted to further elucidate the effector cells involved and utilized clodronate-containing liposomes to deplete the macrophage population ${ }^{24}$ in recipient mice. In line with previously published work ${ }^{37,38}$ clodronate treated mice were unable to eliminate B cells, implicating macrophages as the most likely effectors (Fig. 1d, Supplementary Fig. 2). Finally, to determine whether the difference observed in potency between type I and II mAb could be explained by the so called 'shaving' phenomenon described by Taylor and colleagues $^{39}$, where antibody:CD20 complexes are removed from the cell surface through engagement of CD64, we performed B-cell depletion in a) CD64-/- $\mathrm{x}$ hCD20 $\mathrm{Tg}$ mice 
(not shown) and b) by transfer of hCD20 Tg B cells into wild type or CD64 -/- mice (Fig. 1e) and found no significant effect on the potency of depletion by type I or II mAb. This would suggest that shaving does not play an important role in the in vivo difference between these $\mathrm{mAb}$. These data demonstrate for the first time that both type I and II $\mathrm{mAb}$ utilize the same macrophage- and FcyR-dependent effector mechanism in vivo, and therefore differences in the mechanism of deletion cannot explain the superior potency of type II mAb.

\section{Rituximab rapidly modulates CD20 from the cell surface}

One indication of a critical difference between the activities of the two types of antiCD20 mAb came when CFSE-labeled hCD20 Tg B cells were transferred into $\gamma$-chain -/mice. Here, the absence of activatory Fc $\gamma \mathrm{R}$ prevents deletion of target cells, permitting their study after mAb administration (Fig. 1d). In these experiments CD20 levels were determined by incubating cells with an excess of each anti-CD20 mAb and the same antimouse Fc specific PE- conjugated secondary antibody permitting a direct comparison of $\mathrm{mAb}$ binding levels with a common secondary reagent. In this system, treatment with type I mAb for $16 \mathrm{~h}$ evoked a reduction of approximately $80-90 \%$ in the level of CD20 present on the surface of B-cells whereas type II mAb left CD20 largely unchanged (Fig. 2a). This was confirmed in hCD20 $\mathrm{Tg} \times \gamma$-/- mice (Fig. 2b) where all normal B-cell subsets express hCD20, precluding anomalies within the adoptive transfer model being responsible for the differences. Type I mediated modulation of CD20 was dose dependent in vivo and required the continued presence of $\mathrm{mAb}$ (data not shown and Supplementary Fig. 3). Rapid modulation of CD20 also occurred on purified splenic B-cells in vitro with 
type I but not type II mAb (Fig. 2c). These data, taken with the fact that modulation occurs in $\gamma$-chain -/- (activatory FcR negative) mice and with purified B cells illustrate that this process does not require FcR engagement by effector cells and therefore appears an intrinsic B-cell phenomenon separate from the CD20 shaving reaction ${ }^{40}$. In light of these findings we reassessed the potential of anti-CD20 mAb to mediate phagocytosis of B cells following overnight treatment with $\mathrm{mAb}$ and found that the drop in CD20 surface expression after Rit $\mathrm{m} 2 \mathrm{a}$ treatment resulted in a $50 \%$ loss in the ability of macrophages to capture Ab-coated B cells (Fig. 2d), while B cells treated with tositumomab remained equally sensitive to macrophage attack. These results clearly demonstrate that CD20 modulation by type I mAb impairs their ability to engage critical FcR-dependent effector cells possibly explaining the reduced efficacy of type I mAb in B-cell depletion (Fig. 1a and ${ }^{1}$ ). Although others have previously demonstrated modulation of CD20 from the cell surface as a direct result of mAb ligation ${ }^{21,22}$ we believe this is the first study to demonstrate a potential therapeutic consequence of such B-cell intrinsic modulation.

\section{Rituximab is consumed in vivo}

In addition to reducing the efficiency of effector cell engagement, extensive modulation is also likely to perturb mAb half-life as a result of consumption and degradation by CD20+ B cells. However, we had previously reported that both type I and II mAb halflives in depleting mice were largely equivalent based upon assays using radiolabelled $m A b^{1}$. Given our new findings, we reassessed antibody half-life using a new highly sensitive flow cytometry based assay which, importantly, measures intact, bio-active $\mathrm{mAb}$ (capable of binding $\mathrm{CD} 20+$ cells) in the serum as opposed to measuring 
radioactivity recovered from whole blood which could include degraded, inactive mAb or $\mathrm{mAb}$ internalized by cells giving falsely high readings for type I mAb. In contrast to our previous results, using this system and consistent with the suggestion that modulation will affect mAb consumption, we found that in wild-type mice the half-life of all the mAb was the same at 14 days, but in hCD20 Tg mice, the type I and II mAb persisted with half-lives of 6-7 and 14 days, respectively (Fig $3 a$ and $b$ centre panel). Thus these results correspond with the extent and duration of B-cell depletion seen in Fig. 1 and demonstrate that the faster decay of type I mAb shown in hCD20 $\mathrm{Tg}$ mice is a function of binding to and consumption by CD20+ B cells. Moreover, in hCD20 Tg x $\gamma$-chain -/mice (Fig 3b, right panel), where the anti-CD20 mAb bind to B cells that are not depleted, a similar or slightly accelerated, rate of type I mAb decay was observed, supporting the hypothesis that they are consumed by B cells in an active, antigen specific process which does not require effector cell interactions and excludes a role for shaving by activatory Fc $\gamma \mathrm{R}$-expressing effectors. Further to the observed correlation of mAb halflife and extent of depletion, peripheral B-cell repopulation correlated with the decline in serum mAb levels (Fig. 3c). When mice treated with either type I or II mAb received a repeat dose of the same mAb just as their B cells returned to the circulation (days 40 and 90, respectively), they showed secondary depletion essentially the same as that after primary treatment (Supplementary Fig. 4). This suggests that B cells in type I mAb treated mice are not inherently refractory, but simply that the duration of depletion reflects the kinetics of mAb consumption. In this regard we found that the reduced efficacy of type I mAb can, at least in part, be overcome by maintenance administration. Using a regimen of 25,50 or $100 \mu \mathrm{g} /$ week for 5 weeks, Rit m2a was maintained in the 
serum at much higher levels (approximately 5, 12 and $40 \mu \mathrm{g} / \mathrm{ml}$ respectively at day 40, compared with $2 \mu \mathrm{g} / \mathrm{ml}$ with a single administration; Supplementary Fig. 5), leading to longer lasting depletion of B cells compared with a single dose. However, maintenance dosing, although improving the performance of Rit $\mathrm{m} 2 \mathrm{a}$, still could not equal the depleting efficacy of a single dose of the type II mAb tositumomab at equivalent doses (Fig. 3d).

\section{Modulated rituximab is internalized not shaved}

Although using secondary antibodies to detect surface bound $\mathrm{mAb}$ is able to provide a measure of the surface expression level of CD20, it does not permit the study of the fate of the anti-CD20 mAb. To investigate this more fully we used a method adapted from the surface fluorescence-quenching method of Austin et $\mathrm{al}^{41}$, after comparing these techniques to ensure that they gave similar results (Supplementary Fig. 6). This fluorescence quenching technique permitted us to determine simultaneously the extent of modulation and whether the modulated mAb were internalizing. Firstly we compared whether fluorescently labeled Rit m2a (Rit-488) or tositumomab (Tosit-488) internalized with $\mathrm{CD} 20$ as it modulated from the cell surface. We found that when administered to cells in vitro (Fig. 4a) or in vivo (Fig. 4b), Rit-488 but not Tosit-488 was rapidly internalized as detected by its inaccessibility to surface quenching. Further, splenic B cells from Rit-488 treated mice accumulated appreciable levels of intracellular fluorescence, in marked contrast to results with Tosit-488 (Fig. 4b and 4c left panel). This accumulation resulted in B cells becoming approximately 4 times more strongly stained with Rit-488 than Tosit-488 (Fig. 4b upper panel). Moreover, the Rit-488 was localized 
predominately inside the cells, with little remaining on the surface, whilst the Tosit-488 remained almost exclusively on the cell surface (Fig. 4c lower panel). Internalization correlated with a localized punctate staining pattern, which was also observed in spleen sections after in vivo administration of Rit-488 but not Tosit-488 (Fig. 4c and Supplementary Movie 1). Importantly, type I mAb mediated internalization occurs in wild type Fc $\gamma \mathrm{R}$ expressing hCD20 Tg mice (data not shown) indicating that it occurs in vivo during B-cell depletion. This internalization is an active process requiring permissive temperature, energy production and actin cytoskeletal rearrangements (Fig. 4d). Furthermore, treatment with Rit m2a but not tositumomab leads to a reduction in the total levels of CD20 protein and a concomitant degradation of internalized mAb as detected by the loss of IgG-Alexa488 conjugate (Fig. 4e). CD20 mRNA levels remain relatively constant throughout, suggesting that the cells are unable, at least in the short term, to upregulate CD20 in response to these events (Fig. 4f). Taken together these data provide an explanation for the consumption of rituximab in vivo, the kinetics of its decay in the serum and the concordant recovery of B-cell numbers.

\section{CD20 mAb rapidly internalize and are targeted to the lysosome in normal human B cells and CLL}

Having established the rapid and extensive internalization of type I mAb with hCD20 Tg B cells we sought to clarify whether this was an artifact of this Tg model. Although there have been previous reports demonstrating CD20 internalization with mAb ligation ${ }^{21,22}$ the majority of studies have shown that CD20 does not modulate ${ }^{42,43}$. Indeed, the first clinical use of anti-CD20 mAb, 1F5, by Press and colleagues showed that mAb did not 
undergo antigenic modulation from patient tumor cells and this was highlighted as a benefit of such a reagent ${ }^{44}$. Furthermore, we have reported that CD20 did not substantially modulate from Raji BL cells or a primary CLL sample in a short-term two hour culture ${ }^{45}$. In order to clarify these apparent discrepancies we determined to study modulation on a variety of $\mathrm{B}$ cell targets. Michel and Mattes have previously demonstrated the internalization of CD20 on certain human B-cell lines following $\mathrm{mAb}$ engagement but found it to be slow with little internalization until 18 hours $^{22}$. We found very similar results in our experiments where internalization of CD20 occurred in a panel of 8 human B-cell lines in vitro following Rituximab-488 (Ritux-488) but not Tosit-488 treatment (Fig. 5a), again with internal punctate staining (Fig. 5b), albeit considerably less rapidly than in the hCD20 $\mathrm{Tg}$ mouse B cells. Using these cell lines we were able to confirm $^{22}$ the trafficking of type I CD20 mAb to early endosomes and lysosomes as detected by fluorescent transferrin and Lysotracker ${ }^{\mathrm{TM}}$, respectively (Fig. 5c) illustrating the route of CD20:type I mAb complex internalization and degradation. In sharp contrast, modulation and internalization of CD20:type I mAb occurred much more rapidly in normal human peripheral blood B cells (Fig. 6a) being comparable with that seen in the hCD20 Tg mouse model (Figure 3a). We next examined a panel of primary tumors and revealed marked heterogeneity in the rate of Ritux-488 CD20 internalization. As shown in Figure 6b, CLL cells demonstrated the most rapid kinetics and internalization levels followed by MCL, then FL and finally DLBCL cells, which displayed very little internalization out to 24 hours of culture (Fig. $6 \mathrm{~b}$ and data not shown). For CLL, there was considerable variation in the rate of modulation, with internalization rates straddling that seen in normal B cells. In contrast, FL and DLBCL were generally much slower to 
internalize than CLL ( $<0.05$ at $6 \mathrm{~h})$ with the exception of two outlier FL samples which displayed atypical rapid internalization. This heterogeneity, especially if studying small patient cohorts with mixed tumor types, might help explain some of the confusion as to the tendency of CD20 to be lost from tumor cells. The data also offers the intriguing possibility that modulation of $\mathrm{CD} 20$ by type I mAb might be a useful predictor of therapeutic outcome. For example, it could help explain why SLL, and CLL, which as a rule respond relatively poorly to rituximab, also consume $\mathrm{mAb}$ in larger amounts than equivalent cases of $\mathrm{FL}^{46,47}$. We are currently exploring the mechanisms underlying these differences. Furthermore, the outlier cases of FL which modulate rapidly provide an ideal opportunity to investigate pheno- or geno-typic differences that might control CD20 modulation. However, irrespective of the molecular explanation, the modulation and consumption of type I of anti-CD20 mAb has clear implications for the use of rituximab or non-modulating type II reagents in malignant and autoimmune settings. 


\section{Discussion}

Anti-CD20 immunotherapy is rapidly evolving, with multiple new mAb designed to harness different effector pathways now in clinical trials ${ }^{2}$. The diversity of the mAb being tested reflects the uncertainty regarding the critical mechanism of action for these reagents and which effector pathways should be harnessed for optimal efficacy.

This study demonstrates for the first time that the same Fc:Fc $\gamma \mathrm{R}$ dependent mechanism is critical for the in vivo activity of both type I and type II reagents. Despite this common mode of action it is clear that type II mAb produce more effective B-cell depletion. The approximately 5-fold enhanced efficacy of tositumomab shown here was independent of complement activity or direct induction of apoptosis. Although we cannot entirely rule out the possibility that type II mAb achieve this efficacy in part through the induction of a non-apoptotic cell death pathway, such as described for NHL cell-lines ${ }^{6,8,35}$, we have so far been unable to demonstrate this on isolated hCD20 Tg B-cells (data not shown). Furthermore, cell death through this route does not require additional cross-linking or Fc presence ${ }^{6,8,35}$ and given the lack of depletion in $\gamma$-chain -/- mice and with $\mathrm{F}\left(\mathrm{ab}{ }^{\prime}\right)_{2}$ fragments, it seems unlikely that direct induction of non-apoptotic cell death plays a major role in this model. However, presumably in NHL, both mechanisms will potentially operate to further improve the efficacy of type II vs type I anti-CD20 mAb

The enhanced ability of type II reagents to deplete B cells appears to be related to the fact that they elicit little modulation of CD20 from the cell surface. In contrast, the binding of 
type I mAb induces a profound modulation of $\mathrm{CD} 20$, resulting in two concomitant effects; a reduction in effector cell mediated clearance of B-cells and enhanced mAb consumption.

The literature on CD20 modulation is conflicting, with some reports suggesting that it occurs $^{21,22,48}$, while others have reported that it does not ${ }^{42,43,49}$. These discrepancies may reflect the cell types and different mAb used. In many cases heavily-passaged B-cell lines and xenograft models failed to show significant internalization unless incubated with type I mAb over a long period (e.g. 18-24 h). In contrast, here, human B cells taken from the blood of healthy volunteers underwent internalization with similar kinetics to hCD20 Tg B-cells, within just $2 \mathrm{~h}$. The reasons underlying these differences in kinetics is currently under investigation.

Variable resistance to depletion in vivo may also reflect how long the B cells are coated with type I anti-CD20 mAb and allowed to modulate before they encounter Fc $\gamma \mathrm{R}$ expressing effectors. As such, the length of time prior to encountering tissue resident effector cells or release into the circulation to gain access to the RE could explain the differential sensitivity of B cells in the periphery (most sensitive), bone marrow, and spleen (least sensitive).

It is also possible that internalization may explain the differing sensitivity of B-cell malignancies to rituxumab. We have shown in a cohort of 26 CLL samples treated ex vivo that samples display a range of internalization rates, with some markedly enhanced 
compared with normal B cells. This may predict defective cellular clearance and consumption of large quantities of $\mathrm{mAb}$, as is observed clinically. Furthermore, this wide heterogeneity in modulation rate is likely to explain why we previously concluded that rituximab did not modulate rapidly from the cell surface based upon a far smaller cohort of CLL samples and BL cell lines ${ }^{45}$. Interestingly, while we see some CLL cases which modulate rapidly, for example up to $80 \%$ loss of CD20 at $6 \mathrm{~h}$, we do not see the almost complete loss reported by Jilani et al ${ }^{21}$ after only 1-2 h, which possibly reflects differences in methodology. Interestingly MCL samples also modulated rituximab quite rapidly, in keeping with the relatively poor response of these lymphomas to rituximab treatment. Conversely, FL and DLBCL samples in general demonstrate significantly slower internalization, corresponding with their greater sensitivity to rituximab and consistent with the literature in the field that CD20 is not lost from the cell surface during rituximab treatment. The molecular basis underlying the more rapid internalization seen in $20 \%$ of the FL samples is particularly intriguing and currently under study. Intriguingly, polymorphisms in Fc $\gamma$ RIIIa have been found to correlate with clinical responses to rituximab with $\mathrm{FL}^{50,51}$ but not $\mathrm{CLL}^{52}$. It is tempting to speculate that these associations are related to the rate of modulation observed in each disease, with the rapid modulation observed in CLL potentially negating the enhanced potency of the high affinity Fc $\gamma$ RIIIa allele.

Importantly, the deficiencies of rituximab due to $\mathrm{mAb}$ consumption could be largely overcome by maintenance treatment, suggesting that the reduced level of anti-CD20 mAb bound to 'modulated' targets is still sufficient (albeit not optimal) to trigger deletion by 
effectors. However, this compensation was less apparent in the tissues where maintenance Rit $\mathrm{m} 2 \mathrm{a}$, although improved, was no more effective than a single dose of tositumomab, even when serum mAb levels were higher. Furthermore, our experiments demonstrate that FcR-dependent CD20 shaving does not play an important role in limiting the efficacy of Rit $\mathrm{m} 2 \mathrm{a}$ in the current model, since depletion efficacy was dosedependent and low repeated doses of Rit $\mathrm{m} 2 \mathrm{a}$, as suggested by Taylor et al ${ }^{39}$, did not improve performance. It is important to point out however that shaving may only occur when the RE phagocytic systems such as those of the liver become fully saturated, which may not occur when depleting B cells as opposed to large numbers of tumor cells.

The data presented here suggest that type II mAb may be the most effective in depleting large numbers of B cells as in CLL. Type II mAb are essentially non-modulatory, are not rapidly consumed and maintain their ability to engage FcR-expressing effectors, avoiding the need for multiple dosing regimes and reducing the overall amount of mAb required. An alternative strategy, given the current clinical penetrance of type I mAb, would be to enhance their efficacy by blocking CD20 internalization following treatment, for example by interfering with the membrane fluidity ${ }^{53}$, energy production or the actin machinery of the target cells. Indeed, it is possible that cytotoxic agents act in this way by directly or indirectly affecting such pathways, perhaps helping to explain the efficacy of rituximab in combination with chemo- and radio-therapy.

Recent clinical trials have assessed the efficacy of another type I mAb (ofatumumab) ${ }^{16-18}$ with improved affinity and CDC activity in CLL ${ }^{9,}{ }^{29}$. Interestingly, our preliminary 
analysis (data not shown) indicates that this mAb, in keeping with its type I nature, will also suffer from rapid modulation, although its higher affinity and lower off-rate may provide greater activity at lower mAb serum levels.

In summary, these results suggest that type II anti-CD20 mAb have considerable therapeutic potential in the treatment of B-cell diseases. Until very recently tositumomab was the only type II mAb to have been investigated clinically and this almost exclusively as a radioimmunoconjugate. The second type II reagent, GA101, is currently undergoing clinical trials, with promising effects seen in both CLL and rituximab-treated FL ${ }^{54}$ Importantly, our data suggest an overlooked mechanism for resistance to anti-CD20 $\mathrm{mAb}$. The relevance of this to other target antigens and mAb is unknown but this study highlights the importance of fine specificity in regulating mAb effector functions ${ }^{7}$, and suggests that internalization and consumption may be important criteria for selecting therapeutic mAb. Knowledge of the central pathways involved in modulation should allow the design of rational combination therapies to augment the effect of existing $\mathrm{mAb}$ treatments. 


\section{Acknowledgements}

The authors thank members of the CD20 research team, past and present for their contributions, together with Prof. Tim Illidge, Dr J Teeling and Dr Luke Nolan for the supply of anti-CD20 mAb (tositumomab and rituximab) and cell lines and Prof. Andrew George for insightful discussions. We would like to thank, Prof. Mark Shlomchik for the provision of hCD20 Tg mice, Prof. Marina Botto and Aras Kadioglu for C1q -/- mice and Dr Sjef Verbeek and Prof. Jan van de Winkel for Fc $\gamma \mathrm{R}$-/- mice. Vav-Bcl-2 Tg mice were kindly provided by Dr George Hacker and Professor Jerry Adams. We are also grateful to Dr Kathleen N. Potter, Dr Ian C. Mockridge, Isla Wheatley and the Dept of Health/CR UK ECMC for provision and assistance with clinical material. Funding was provided by Leukaemia Research grants 07048 and 07010, an MRC fellowship to SHL, CRUK grants C328/A2738 and C328/A2737 and Tenovus, Cardiff.

\section{Author contributions}

SAB designed the research, performed experiments, analyzed results, produced figures and wrote the paper with MSC; RRF performed experiments, produced figures and edited the manuscript; CHTC produced critical reagents; TCJ, RMV, SSW, SVD, JHJK, KLC, JPK, SHL and DAJ performed experiments; PWMJ analyzed results and edited the manuscript; MJG designed the research, analyzed results and edited the manuscript; MSC designed the research, analyzed results and wrote the manuscript with SAB.

Conflict of interest disclosure: The authors declare no competing financial interests. 


\section{References}

1. Beers $\mathrm{SA}$, Chan $\mathrm{CH}$, James $\mathrm{S}$, et al. Type II (tositumomab) anti-CD20 monoclonal antibody out performs type I (rituximab-like) reagents in B-cell depletion regardless of complement activation. Blood. 2008;112(10):4170-4177.

2. Lim SH, Beers SA, French RR, Johnson PWM, Glennie MJ, M.S C. Anti-CD20 monoclonal antibodies - historical and future perspectives. Haematologica. 2009; In press.

3. Clynes RA, Towers TL, Presta LG, Ravetch JV. Inhibitory Fc receptors modulate in vivo cytoxicity against tumor targets. Nature medicine. Apr 2000;6(4):443-446.

4. Nimmerjahn F, Ravetch JV. Antibodies, Fc receptors and cancer. Current opinion in immunology. 2007;19(2):239-245.

5. Glennie MJ, French RR, Cragg MS, Taylor RP. Mechanisms of killing by antiCD20 monoclonal antibodies. Mol Immunol. 2007;44(16):3823-3837.

6. Chan HT, Hughes D, French RR, et al. CD20-induced lymphoma cell death is independent of both caspases and its redistribution into triton X-100 insoluble membrane rafts. Cancer research. 2003;63(17):5480-5489.

7. Cragg MS, Glennie MJ. Antibody specificity controls in vivo effector mechanisms of anti-CD20 reagents. Blood. 2004;103(7):2738-2743.

8. Ivanov A, Beers SA, Walshe CA, et al. Homotypic adhesion and lysosomemediated cell death evoked by anti-CD20 (Tositumomab) and HLA DR monoclonal antibodies Journal of Clinical Investigation. 2009; In press.

9. Teeling JL, Mackus WJ, Wiegman LJ, et al. The biological activity of human CD20 monoclonal antibodies is linked to unique epitopes on CD20. J Immunol. 2006;177(1):362-371.

10. Polyak MJ, Deans JP. Alanine-170 and proline-172 are critical determinants for extracellular CD20 epitopes; heterogeneity in the fine specificity of CD20 monoclonal antibodies is defined by additional requirements imposed by both amino acid sequence and quaternary structure. Blood. 2002;99(9):3256-3262.

11. Illidge TM, Bayne M, Brown NS, et al. Phase $1 / 2$ study of fractionated (131)Irituximab in low-grade B-cell lymphoma: the effect of prior rituximab dosing and tumor burden on subsequent radioimmunotherapy. Blood. 2009;113(7):14121421.

12. Dayde $\mathrm{D}$, Ternant $\mathrm{D}$, Ohresser $\mathrm{M}$, et al. Tumor burden influences exposure and response to rituximab: pharmacokinetic-pharmacodynamic modeling using a syngeneic bioluminescent murine model expressing human CD20. Blood. 2009;113(16):3765-3772.

13. Lin TS, Lucas MS, Byrd JC. Rituximab in B-cell chronic lymphocytic leukemia. Semin Oncol. 2003;30(4):483-492.

14. O'Brien SM, Kantarjian H, Thomas DA, et al. Rituximab dose-escalation trial in chronic lymphocytic leukemia. J Clin Oncol. 2001;19(8):2165-2170.

15. Piro LD, White CA, Grillo-Lopez AJ, et al. Extended Rituximab (anti-CD20 monoclonal antibody) therapy for relapsed or refractory low-grade or follicular non-Hodgkin's lymphoma. Ann Oncol. 1999;10(6):655-661. 
16. Coiffier B, Lepretre S, Pedersen LM, et al. Safety and efficacy of ofatumumab, a fully human monoclonal anti-CD20 antibody, in patients with relapsed or refractory B-cell chronic lymphocytic leukemia: a phase 1-2 study. Blood. 2008;111(3):1094-1100.

17. Coiffier B, Tilly H, Pedersen LM, et al. Significant Correlation between Survival Endpoints and Exposure to Ofatumumab (HuMax-CD20) in Chronic Lymphocytic Leukemia. ASH Annual Meeting Abstracts. 2006;108(11):2842-.

18. Coiffier B, Tilly H, Pedersen LM, et al. HuMax CD20 Fully Human Monoclonal Antibody in Chronic Lymphocytic Leuchemia. Early Results from an Ongoing Phase I/II Clinical Trial. ASH Annual Meeting Abstracts. 2005;106(11):448-.

19. Huh YO, Keating MJ, Saffer HL, Jilani I, Lerner S, Albitar M. Higher levels of surface CD20 expression on circulating lymphocytes compared with bone marrow and lymph nodes in B-cell chronic lymphocytic leukemia. Am J Clin Pathol. 2001;116(3):437-443.

20. Manshouri T, Do KA, Wang X, et al. Circulating CD20 is detectable in the plasma of patients with chronic lymphocytic leukemia and is of prognostic significance. Blood. 2003;101(7):2507-2513.

21. Jilani I, O'Brien S, Manshuri T, et al. Transient down-modulation of CD20 by rituximab in patients with chronic lymphocytic leukemia. Blood. 2003;102(10):3514-3520.

22. Michel RB, Mattes MJ. Intracellular accumulation of the anti-CD20 antibody 1F5 in B-lymphoma cells. Clin Cancer Res. 2002;8(8):2701-2713.

23. Glennie MJ, McBride HM, Worth AT, Stevenson GT. Preparation and performance of bispecific $\mathrm{F}\left(\mathrm{ab}^{\prime}\right.$ gamma)2 antibody containing thioether-linked Fab' gamma fragments. J Immunol. 1987;139(7):2367-2375.

24. Van Rooijen N, Sanders A. Kupffer cell depletion by liposome-delivered drugs: comparative activity of intracellular clodronate, propamidine, and ethylenediaminetetraacetic acid. Hepatology (Baltimore, Md.) 1996;23(5):12391243.

25. Tutt AL, French RR, Illidge TM, et al. Monoclonal antibody therapy of B cell lymphoma: signaling activity on tumor cells appears more important than recruitment of effectors. J Immunol. 1998;161(6):3176-3185.

26. Walshe CA, Beers SA, French RR, et al. Induction of cytosolic calcium flux by CD20 is dependent upon B Cell antigen receptor signaling. J Biol Chem. 2008;283(25):16971-16984.

27. Ahuja A, Shupe J, Dunn R, Kashgarian M, Kehry MR, Shlomchik MJ. Depletion of B cells in murine lupus: efficacy and resistance. J Immunol. 2007;179(5):33513361.

28. Golay J, Zaffaroni L, Vaccari T, et al. Biologic response of B lymphoma cells to anti-CD20 monoclonal antibody rituximab in vitro: CD55 and CD59 regulate complement-mediated cell lysis. Blood. 2000;95(12):3900-3908.

29. Teeling JL, French RR, Cragg MS, et al. Characterization of new human CD20 monoclonal antibodies with potent cytolytic activity against non-Hodgkin lymphomas. Blood. 2004;104(6):1793-1800. 
30. Janas E, Priest R, Wilde JI, White JH, Malhotra R. Rituxan (anti-CD20 antibody)induced translocation of CD20 into lipid rafts is crucial for calcium influx and apoptosis. Clinical and experimental immunology. 2005;139(3):439-446.

31. Stolz C, Hess G, Hahnel PS, et al. Targeting Bcl-2 family proteins modulates the sensitivity of B-cell lymphoma to rituximab-induced apoptosis. Blood. 2008;112(8):3312-3321.

32. Egle A, Harris AW, Bath ML, O'Reilly L, Cory S. VavP-Bcl2 transgenic mice develop follicular lymphoma preceded by germinal center hyperplasia. Blood. 2004;103(6):2276-2283.

33. Uchida J, Hamaguchi Y, Oliver JA, et al. The innate mononuclear phagocyte network depletes B lymphocytes through Fc receptor-dependent mechanisms during anti-CD20 antibody immunotherapy. J Exp Med. 2004;199(12):1659-1669.

34. Hamaguchi Y, Uchida J, Cain DW, et al. The peritoneal cavity provides a protective niche for $\mathrm{B} 1$ and conventional $\mathrm{B}$ lymphocytes during anti-CD20 immunotherapy in mice. J Immunol. 2005;174(7):4389-4399.

35. Ivanov A, Krysov S, Cragg MS, Illidge T. Radiation therapy with tositumomab (B1) anti-CD20 monoclonal antibody initiates extracellular signal-regulated kinase/mitogen-activated protein kinase-dependent cell death that overcomes resistance to apoptosis. Clin Cancer Res. 2008;14(15):4925-4934.

36. Mossner E, Brunker P, Moser S, et al. Increasing the efficacy of CD20 antibody therapy through the engineering of a new type II anti-CD20 antibody with enhanced direct- and immune effector cell-mediated B-cell cytotoxicity. Blood. Mar 12010.

37. Gong $\mathrm{Q}, \mathrm{Ou} \mathrm{Q}, \mathrm{Ye} \mathrm{S}$, et al. Importance of cellular microenvironment and circulatory dynamics in B cell immunotherapy. J Immunol. 2005;174(2):817-826.

38. Minard-Colin V, Xiu Y, Poe JC, et al. Lymphoma depletion during CD20 immunotherapy in mice is mediated by macrophage FcgammaRI, FcgammaRIII, and FcgammaRIV. Blood. 2008;112(4):1205-1213.

39. Beum PV, Kennedy AD, Williams ME, Lindorfer MA, Taylor RP. The shaving reaction: rituximab/CD20 complexes are removed from mantle cell lymphoma and chronic lymphocytic leukemia cells by THP-1 monocytes. J Immunol. 2006;176(4):2600-2609.

40. Li Y, Williams ME, Cousar JB, Pawluczkowycz AW, Lindorfer MA, Taylor RP. Rituximab-CD20 complexes are shaved from Z138 mantle cell lymphoma cells in intravenous and subcutaneous SCID mouse models. $J$ Immunol. 2007;179(6):4263-4271.

41. Austin CD, De Maziere AM, Pisacane PI, et al. Endocytosis and sorting of ErbB2 and the site of action of cancer therapeutics trastuzumab and geldanamycin. $\mathrm{Mol}$ Biol Cell. 2004;15(12):5268-5282.

42. Press OW, Farr AG, Borroz KI, Anderson SK, Martin PJ. Endocytosis and degradation of monoclonal antibodies targeting human B-cell malignancies. Cancer research. 1989;49(17):4906-4912.

43. Press OW, Howell-Clark J, Anderson S, Bernstein I. Retention of B-cell-specific monoclonal antibodies by human lymphoma cells. Blood. 1994;83(5):1390-1397.

44. Press OW, Appelbaum F, Ledbetter JA, et al. Monoclonal antibody 1F5 (antiCD20) serotherapy of human B cell lymphomas. Blood. 1987;69(2):584-591. 
45. Cragg MS, Bayne MC, Illidge TM, Valerius T, Johnson PW, Glennie MJ. Apparent modulation of CD20 by rituximab: an alternative explanation. Blood. 2004;103(10):3989-3990; author reply 3990-3981.

46. McLaughlin P, Grillo-Lopez AJ, Link BK, et al. Rituximab chimeric anti-CD20 monoclonal antibody therapy for relapsed indolent lymphoma: half of patients respond to a four-dose treatment program. J Clin Oncol. 1998;16(8):2825-2833.

47. Keating MJ, O'Brien S, Albitar M. Emerging information on the use of rituximab in chronic lymphocytic leukemia. Semin Oncol. 2002;29(1 Suppl 2):70-74.

48. Luqman M, Klabunde S, Lin K, et al. The antileukemia activity of a human antiCD40 antagonist antibody, HCD122, on human chronic lymphocytic leukemia cells. Blood. 2008;112(3):711-720.

49. Vervoordeldonk SF, Merle PA, van Leeuwen EF, von dem Borne AE, SlaperCortenbach IC. Preclinical studies with radiolabeled monoclonal antibodies for treatment of patients with B-cell malignancies. Cancer. 1994;73(3 Suppl):10061011.

50. Cartron G, Dacheux L, Salles G, et al. Therapeutic activity of humanized antiCD20 monoclonal antibody and polymorphism in IgG Fc receptor FcgammaRIIIa gene. Blood. 2002;99(3):754-758.

51. Weng WK, Levy R. Two immunoglobulin $\mathrm{G}$ fragment $\mathrm{C}$ receptor polymorphisms independently predict response to rituximab in patients with follicular lymphoma. J Clin Oncol. 2003;21(21):3940-3947.

52. Farag SS, Flinn IW, Modali R, Lehman TA, Young D, Byrd JC. Fc gamma RIIIa and Fc gamma RIIa polymorphisms do not predict response to rituximab in B-cell chronic lymphocytic leukemia. Blood. 2004;103(4):1472-1474.

53. Lam WA, Rosenbluth MJ, Fletcher DA. Chemotherapy exposure increases leukemia cell stiffness. Blood. 2007;109(8):3505-3508.

54. Salles GA, Morschhauser F, Cartron G, et al. A Phase I/II Study of RO5072759 (GA101) in Patients with Relapsed/Refractory CD20+ Malignant Disease. ASH Annual Meeting Abstracts. 2008;112(11):234-. 


\section{Figure Legends}

Figure 1. Type II anti-CD20 mAb deplete B-cells more effectively than type I mAb via a complement and apoptosis-independent mechanism that requires Fc:FcR engagement. a) Systemic depletion: hCD20 Tg mice (BALB/c background) received 250 $\mu \mathrm{g}$ anti-CD20 mAb or isotype matched control i.v. on day 0 and the number of circulating B-cells assessed. Points show means, $n \geq 4$ mice for each time point from 2-4 independent experiments. b) Adoptive transfer: hCD20 Tg target (T) or WT non-target (NT) BALB/c splenocytes labeled with high or low CFSE, respectively were injected i.v. into $\mathrm{BALB} / \mathrm{c}$ mice. $24 \mathrm{~h}$ later mice received $\mathrm{mAb}(1 \mu \mathrm{g}$, i.v. $)$ and $16 \mathrm{~h}$ later spleens analyzed to determine the T:NT ratio. Left panel: bars represent mean +/- s.d., $n=3-5$ mice for each treatment group. * both type II mAb significantly differ from both type I mAb: Rit m2a vs FGM6, p< 0.02; Rit m2a vs Tosit $\mathrm{p}<0.002$; 1F5 vs FGM6 and 1F5 vs Tosit, $\mathrm{p}<0.005$. Right panel: typical dot-plot data. c) Dose response to Rit $\mathrm{m} 2 \mathrm{a}$ and tositumomab (Tosit) in a similar adoptive transfer: bars represent mean and range, $\mathrm{n}=2$ mice at each concentration. d) Contribution of effector mechanisms: Ctl, transfer of T and NT into WT recipients as above; CDC, NT and T cells transferred into complementdeficient (C1q-/- and C3-/-) mice; PCD, hCD20 Tg and hCD20 x Vav-Bcl-2 double Tg (both T), and WT (NT) labeled with high CFSE, low CFSE and PKH26 respectively transferred into WT mice and the level of both T compared with the NT; Fc:Fc $\gamma \mathrm{R}, \mathrm{T}$ and NT cells transferred into $\gamma$-/- or clodronate-treated (Clod) WT mice; also shown is the activity of $\mathrm{F}\left(\mathrm{ab}^{\prime}\right)_{2}$ fragments in WT recipients. Bars represent mean +/- s.d., $\mathrm{n}=3$ mice for each treatment group; each condition is representative of at least 2 independent experiments. e) Poor type I depletion is not due to shaving: Transfer of T and NT cells 
into WT and CD64 -/- mice as described above with Ctl, Rit m2a or Tosit mAb. Bars represent mean and range, $\mathrm{n}=2$ mice for each treatment group; representative of at least 2 independent experiments.

Figure 2. Type I mAb treatment results in modulation of CD20 from the cell surface both in vivo and in vitro. a) hCD20 Tg B cells transferred into non-depleting $\gamma$-/- mice as in Fig. 1c were assessed $16 \mathrm{~h}$ after mAb treatment for CD20 surface expression by detecting bound mAb with PE-labeled anti-mouse Fc. Red, Rit m2a; blue, tositumomab; solid, background. Top histogram, CD20 expression on B cells from untreated mice labeled with Rit m2a and tositumomab ex-vivo; bottom histogram, CD20 expression after treatment with Rit m2a or tositumomab in-vivo. Bar chart; CD20 expression after treatment with type I and type II mAb; bars represent mean $+/$ - s.d., $\mathrm{n} \geq 3$ mice, one of at least 3 experiments. * Rit m2a and 1F5 significantly differ from FGM6 and tositumomab, $\mathrm{p}<0.0001$. b) Surface CD20 expression on peripheral B-cells in hCD20 Tg $\gamma$-chain -/mice after mAb treatment $(250 \mu \mathrm{g})$; red, Rit m2a; blue, tositumomab; solid, background; black, untreated. c) Loss of surface CD20 in vitro. Isolated splenic hCD20 Tg B Cells were incubated with Rit $\mathrm{m} 2 \mathrm{a}$ or tositumomab $(10 \mu \mathrm{g} / \mathrm{ml})$ before detecting surface CD20. Bars represent mean and range for 2 experiments each performed in triplicate. d) Phagocytic potential is reduced by treatment of CD20 Tg B-cells with Rit m2a. Cells were treated for $16 \mathrm{~h}$ with $\mathrm{mAb}$, labeled with CFSE, incubated with bone marrow-derived macrophages, and then APC-F4/80 labeled before flow cytometry to detect double +ve macrophages (left hand panel) or confocal microscopy (right hand panel). As shown in c), $16 \mathrm{~h}$ incubation with Rit m2a but not tositumomab caused loss of CD20 and resulted 
in a reduction in the number of double $+v e$ macrophages $(*, p<0.0001)$. Bars represent mean +/- s.e.m. of triplicate samples, one of 3 similar experiments. Right hand panel shows a typical image of macrophages capturing and engulfing CFSE-labeled B-cells coated with tositumomab.

Figure 3. Serum mAb levels correlate with B-cell depletion kinetics. a) and b) WT, hCD20 Tg, and CD20 Tg $\gamma$-chain -/- mice were treated with mAb (250 $\mu \mathrm{g})$, and the serum mAb concentration measured after 1,7 and 28 days by incubating sera with SU-DHL-4 cells and then detecting cell-bound mAb with FITC-labeled anti-mouse $\mathrm{Fc}$, and comparing the level with a standard curve. a) shows representative histograms; solid histogram, background staining; blue, type II mAb tositumomab; red and green, type I $\mathrm{mAb}$ Rit $\mathrm{m} 2 \mathrm{a}$ and $1 \mathrm{~F} 5$, respectively. $\mathrm{b}$ ) shows the concentration of $\mathrm{mAb}$ in the serum. $\mathrm{n}$ $=3$ mice per group, bars show mean $+/$ - s.d. c) Correlation of serum mAb levels and Bcell repopulation in the periphery. hCD20 Tg mice were treated with a single dose of $\mathrm{mAb}(250 \mu \mathrm{g})$ and the $\mathrm{mAb}$ level in the serum and B cell numbers assessed. Bars show mean $+/$ - s.d., $\mathrm{n}=3$ mice per group. d) Repeated low level dosing (25, 50 or $100 \mu \mathrm{g}$ weekly for 5 weeks) with Rit m2a potentiates B-cell depletion compared to a single large dose $(250 \mu \mathrm{g})$ of $\mathrm{mAb}$ to a level equivalent to that seen with tositumomab. The level of B-cells in the blood and secondary lymphoid organs was assessed on day 40 by flow cytometry and IHC staining for T (blue) and B (yellow) cells. Serum mAb levels were also assessed (Supplementary Figure 5) with repeated doses shown to enhance mAb serum levels. 
Figure 4. Type I mAb modulate CD20 from the cell surface through internalization, leading to mAb and CD20 degradation. a) hCD20 Tg B cells were incubated in vitro with Rit m2a-Alexa488 (Rit-488) or Tosit-Alexa488 (Tosit-488) mAb (5 $\mu \mathrm{g} / \mathrm{ml})$ for 1, 2 or $6 \mathrm{~h}$, washed, then incubated in the presence or absence of anti-Alexa488 quenching $\mathrm{Ab}$. The fluorescence remaining after quenching indicates the proportion of internalized $\mathrm{mAb}$ (histogram upper panel). Bars represent mean with range for duplicate determinations, one of three similar experiments. b) hCD20 $\operatorname{Tg} \times \gamma-/$ mice were administered Rit-488 or Tosit-488 (100 $\mu$ g) i.v. and the amount of fluorescence associated with splenic B cells was assessed $24 \mathrm{~h}$ later (upper panel), Rit-488 treated B cells accumulated approximately $4 \mathrm{x}$ the fluorescence compared with that of Tosit- 488 treated mice ( $\mathrm{n}=3$ mice). Despite the Rit m2a treated B cells having a higher level of Bcell associated fluorescence, the Tosit treated B cells (blue) expressed more CD20 on their surface than Rit-488 treated cells (red)(lower panel), histograms from one of three similar experiments. c) Left panel, in vivo treatment: $10 \mu \mathrm{m}$ spleen sections from mice treated as in b) were analyzed by confocal microscopy. Assessed at the same gain intensity, far greater mAb accumulation is evident after Rit m2a (upper panels), with its more punctate staining apparent when Rit $\mathrm{m} 2 \mathrm{a}$ and Tosit were compared at optimized gain intensity (lower panels). Right panel, in vitro treatment: hCD20 Tg B-cells treated with Rit-488 (5 $\mu \mathrm{g} / \mathrm{ml})$ in vitro and assessed by confocal microscopy with a maximal projection, $\mathrm{Z}$ section through the centre of the cell and overlaid versus the bright field (Bf). d) Internalization of Rit-488 or Tosit-488 on hCD20 $\mathrm{Tg}$ B cells under normal conditions (NT), at $4^{\circ} \mathrm{C}$, in the presence of azide $(\mathrm{Azd}, 15 \mathrm{mM})$ or latrunculin $\mathrm{B}$ (Lat B, $50 \mu \mathrm{M})$. Bars represent mean with range for duplicate determinations, one of three similar 
experiments. e) hCD20 Tg B cells treated with Rit-488 or Tosit-488 for 6 h and assessed by western blot for the expression of intact Alexa488- IgG, CD20 and actin (as a loading control). f) mRNA levels of CD20 and GAPDH (as a control) were assessed in the same cells.

Figure 5. Type I mAb internalize in human cell-lines and traffic to the lysosome. a) A selection of NHL cell-lines (Raji, Daudi, SUDHL4, DOHH2, Ramos, Granta-519, RL, HBL-1) were treated with Rituximab-Alexa488 (Ritux-488) or Tosit-488 (5 $\mu \mathrm{g} / \mathrm{ml})$ for 2 , 6 or $24 \mathrm{~h}$ and then assessed for internalization as before. At each time point, the level of surface accessible CD20 with Ritux-488 was significantly lower than with Tosit-488; 2 h, p<0.001, 6 and 24 h, p<0.0001. b) Appearance of Raji B cells treated with Ritux-488 or Tosit-488 $(5 \mu \mathrm{g} / \mathrm{ml})$ for $24 \mathrm{~h}$ in vitro and assessed by confocal microscopy with a $\mathrm{Z}$ section through the centre of the cell and overlaid versus the bright field (Bf). c) Colocalisation of Ritux-488 with transferrin-647 or Lysostracker ${ }^{\mathrm{TM}}$ on Raji cells.

Figure 6. Type I mAb internalize in primary normal and malignant human B-cells.

a) Normal human peripheral blood B-cells were isolated by negative selection, treated with Ritux-488 or Tosit-488, $(5 \mu \mathrm{g} / \mathrm{ml})$ for 2,6 or $24 \mathrm{~h}$ and then assessed for internalization as before. Results from 8 different donors are shown. At each time point, the level of surface accessible CD20 with Ritux-488 was significantly lower than with Tosit-488, p<0.0001. b) CLL, MCL, FL or DLBCL samples were treated with Ritux-488 or Tosit-488 $(5 \mu \mathrm{g} / \mathrm{ml})$ for 2 or $6 \mathrm{~h}$ and then assessed for internalization as before. The amount of surface accessible CD20 after Ritux-488 was significantly lower than after 
Tosit-488 at $6 \mathrm{~h}$ for CLL, MCL and FL; $\mathrm{p}<0.0001 ; \mathrm{p}<0.0013$; and $\mathrm{p}<0.006$, respectively. The table shows the significance of the difference in the rate of internalization of Ritux-488 between CLL and other disease subtypes. Each data point represents a sample from a different patient; CLL $\mathrm{n}=26, \mathrm{MCL} \mathrm{n}=5, \mathrm{FL} \mathrm{n}=9$ and $\operatorname{DLBCL} \mathrm{n}=5$. 
A

B

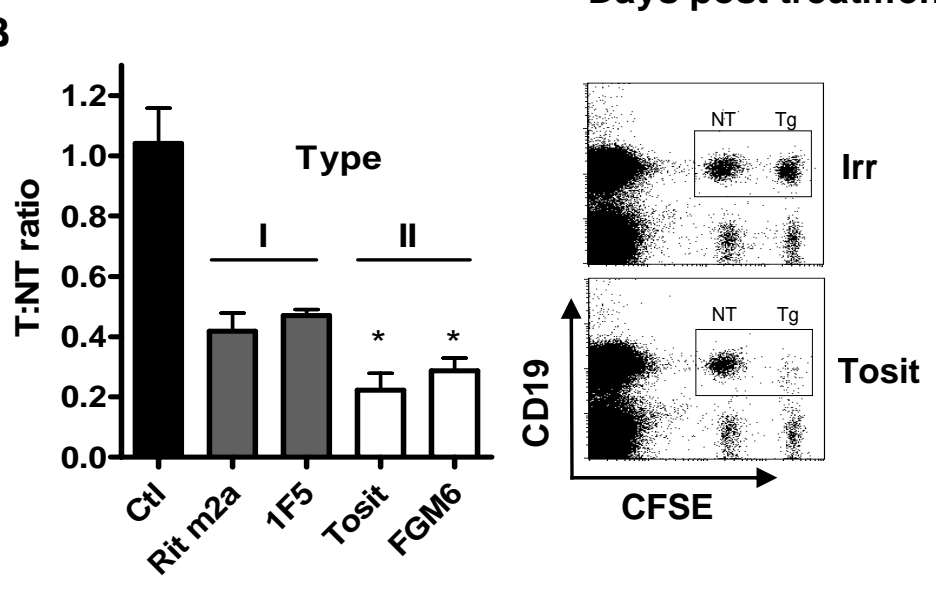

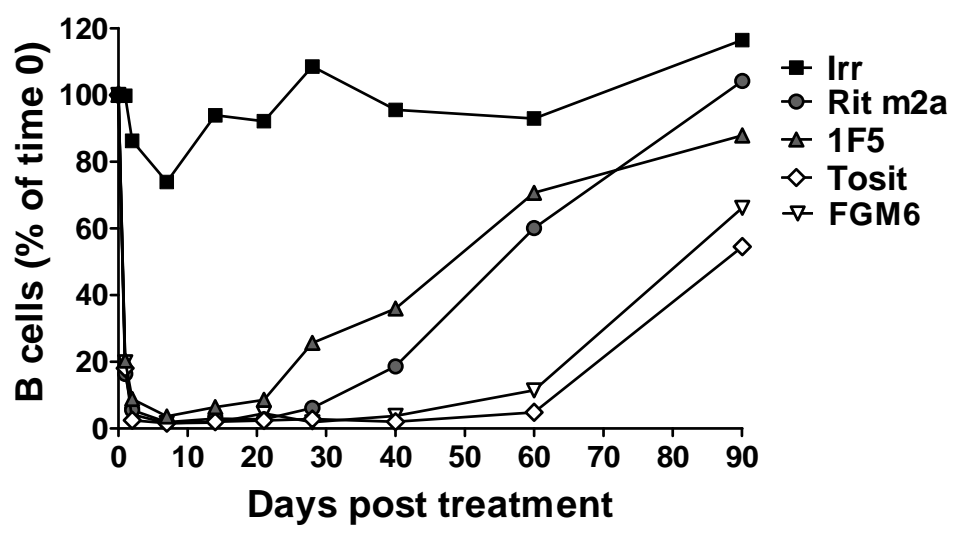
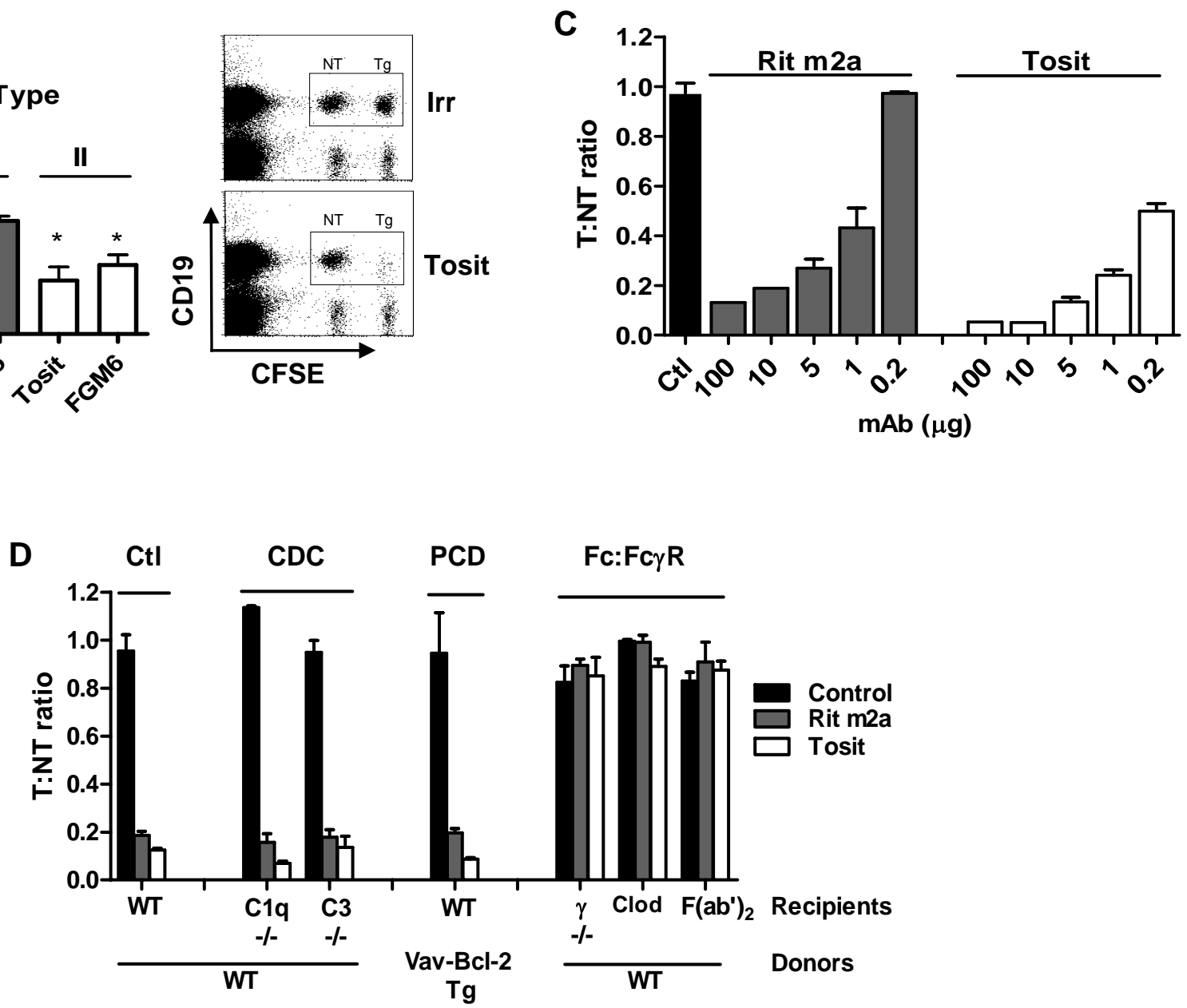

E

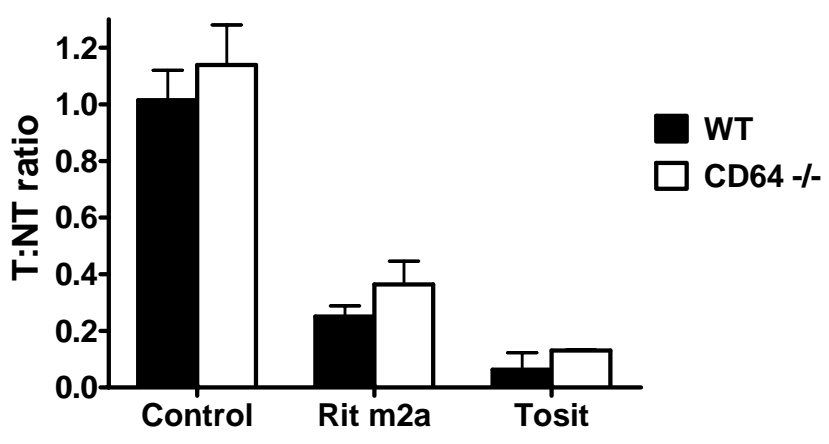

Figure 1. 
A
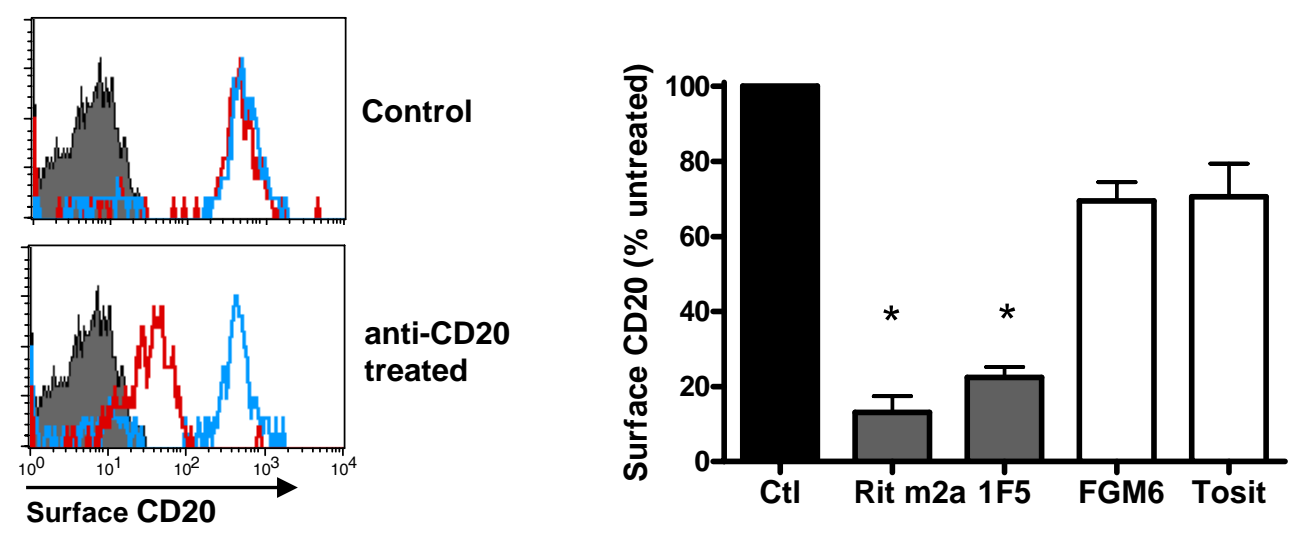

B
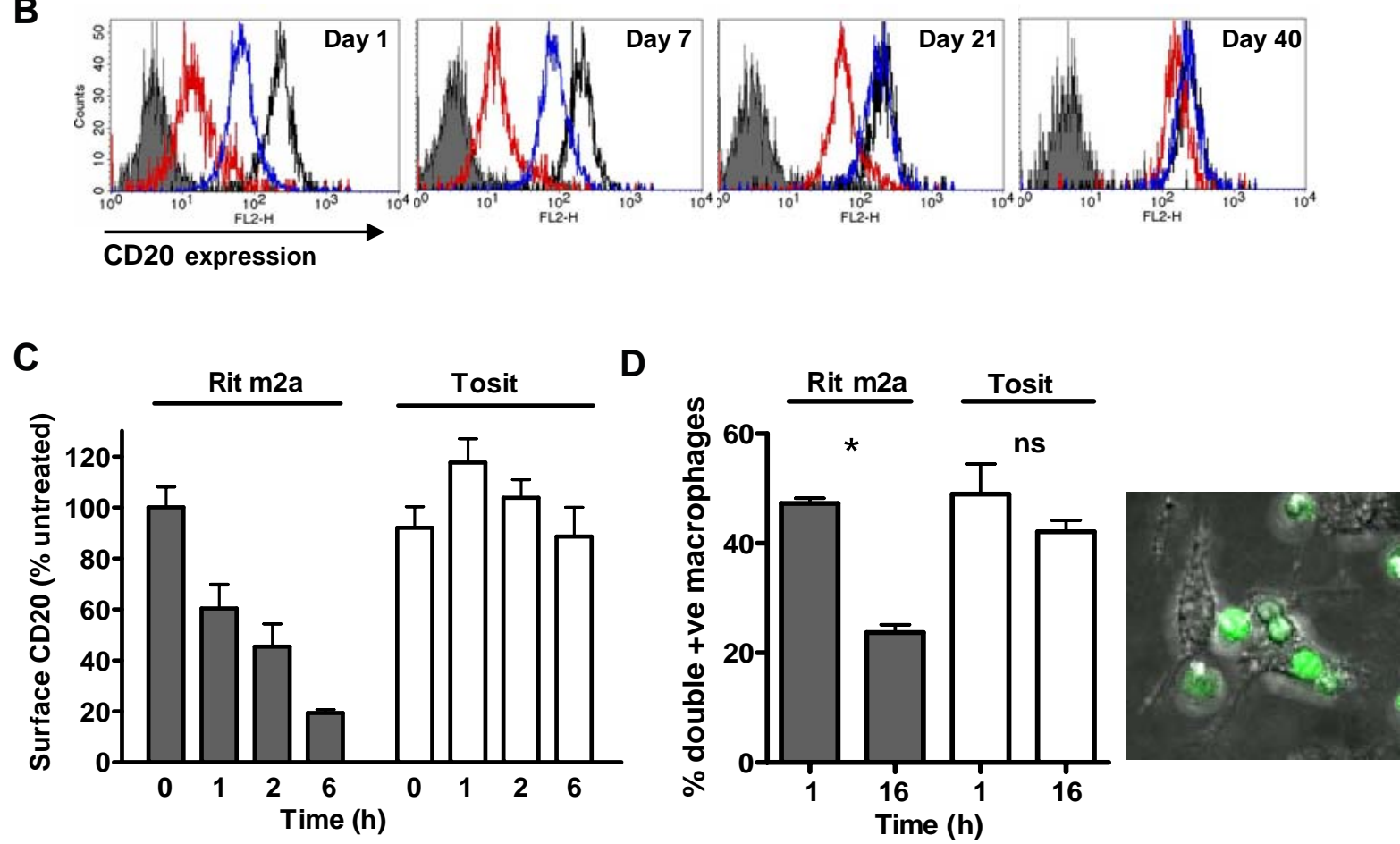

Figure 2. 
A

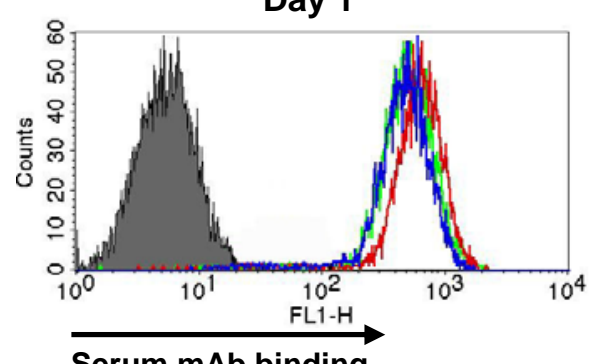

Serum mAb binding

B

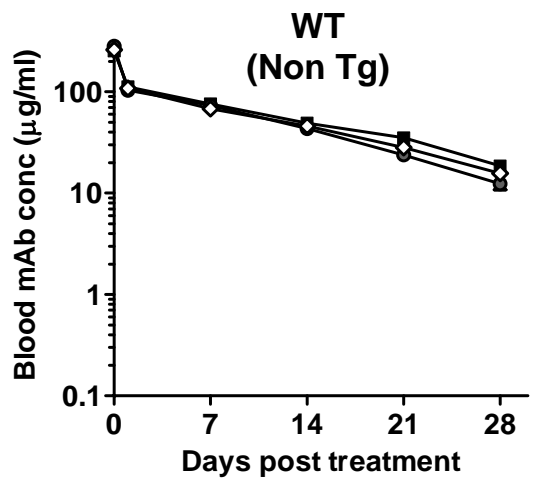

C

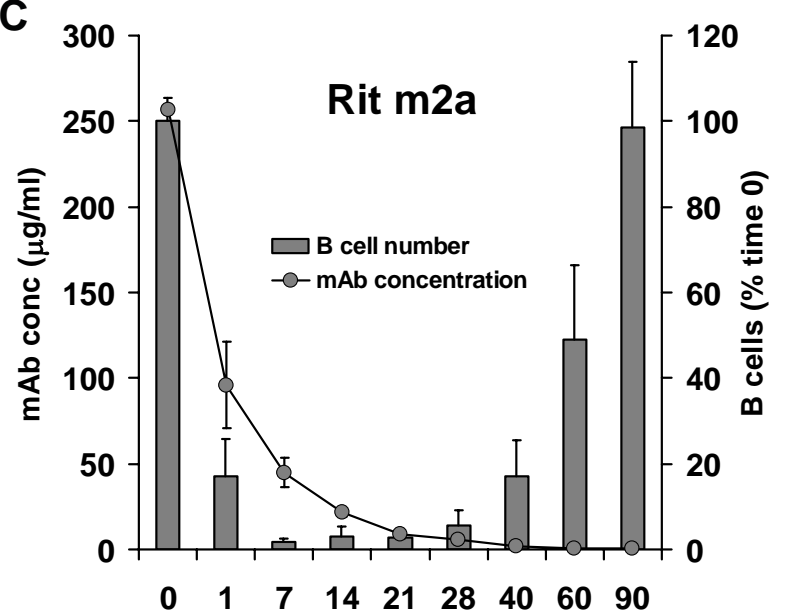

Days post treatment

D

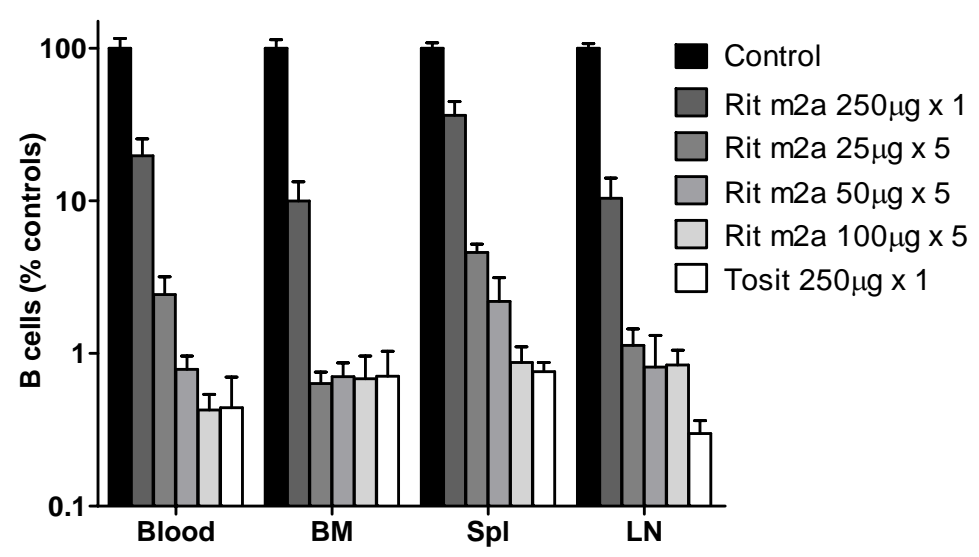

Day 7
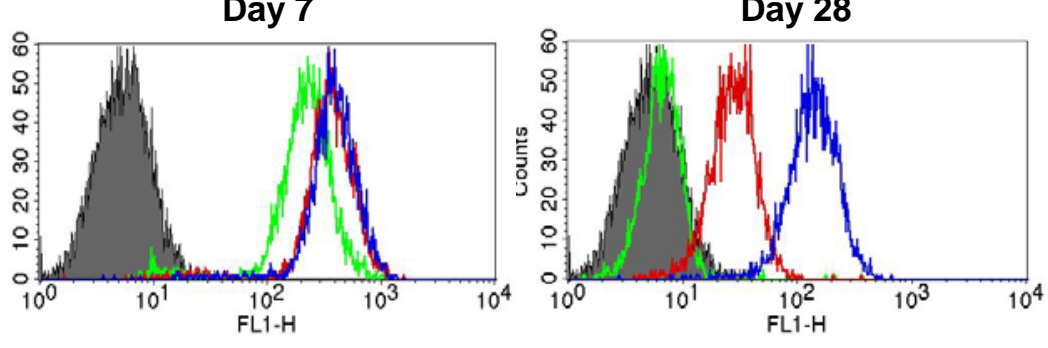
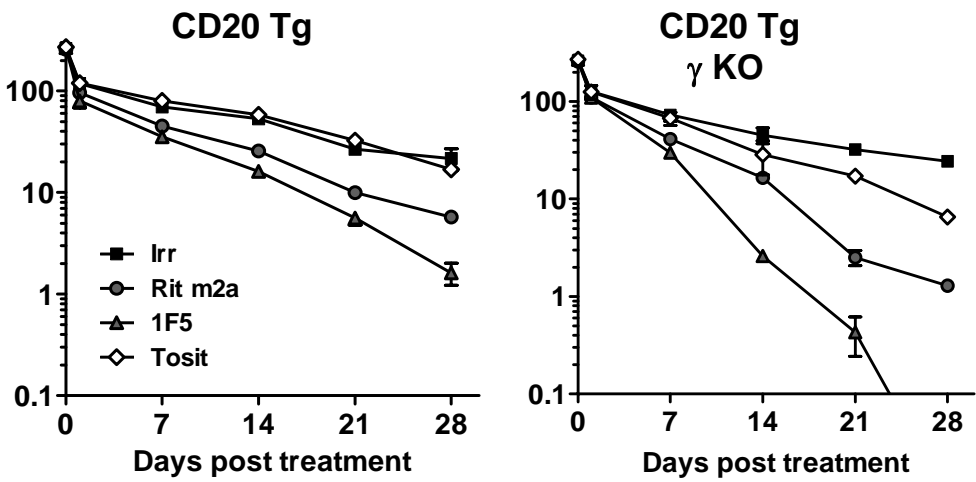

Days post treatment

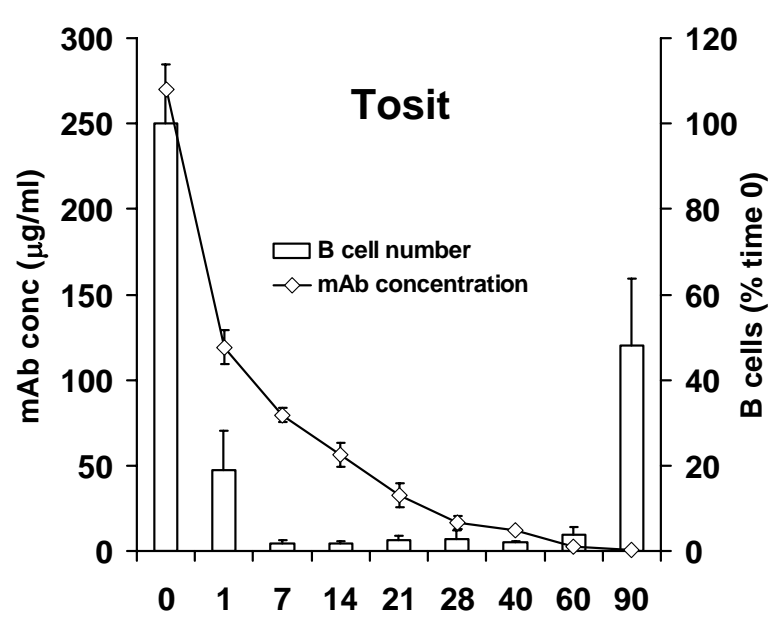

Days post treatment

Day 40 spleens

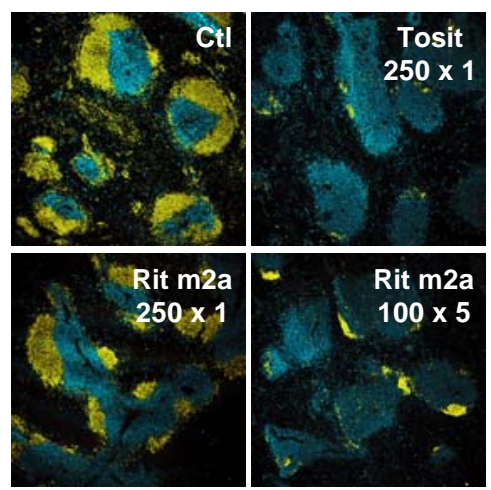

Figure 3. 
A

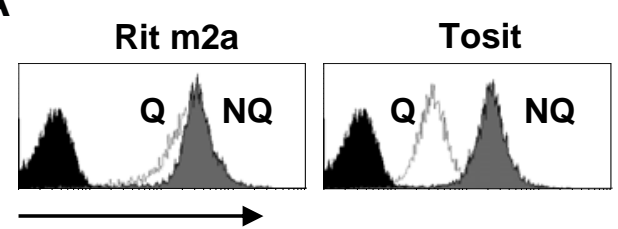

mAb-488

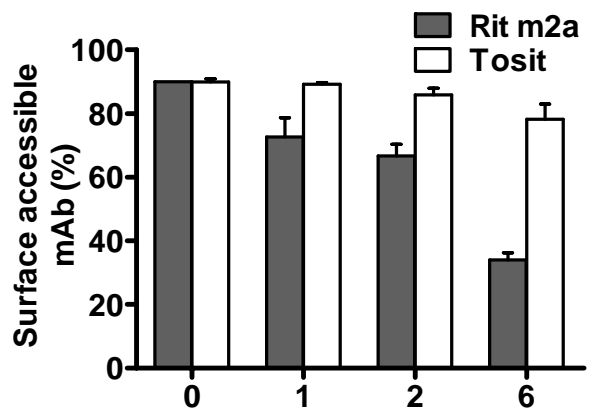

C

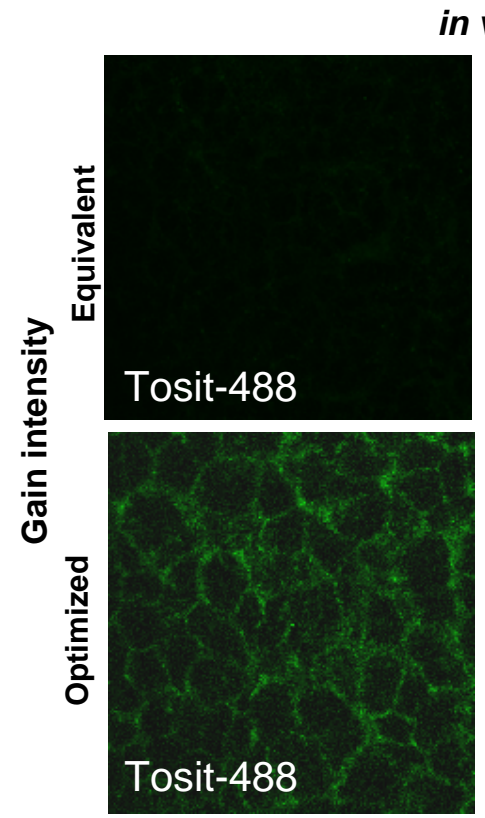

in vivo

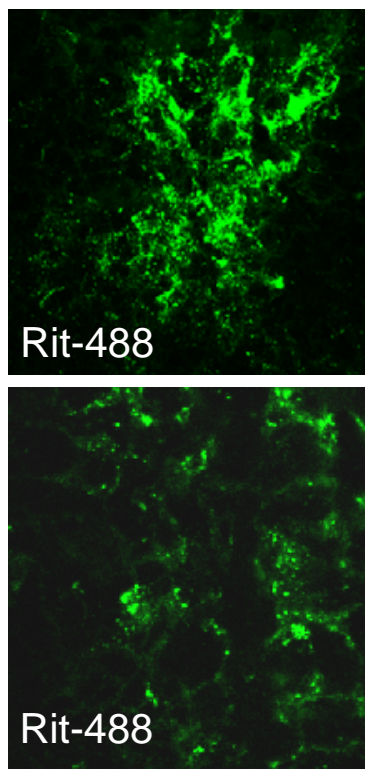

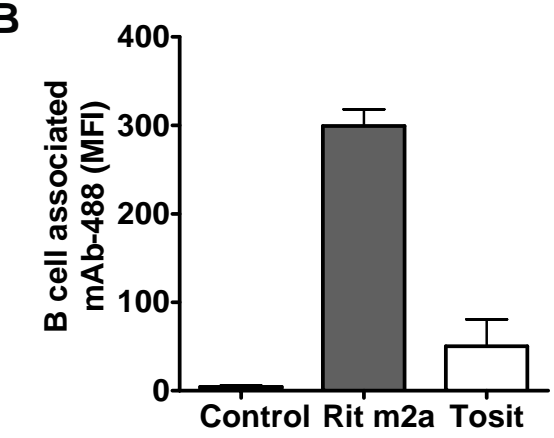

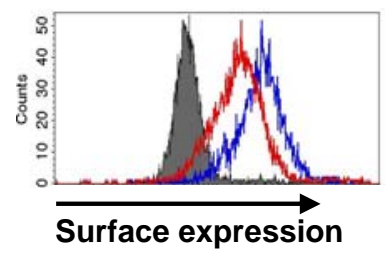

in vitro

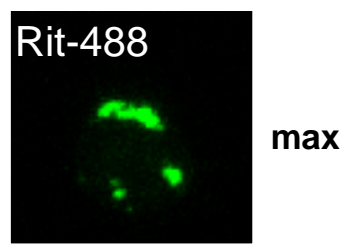

Rit-488

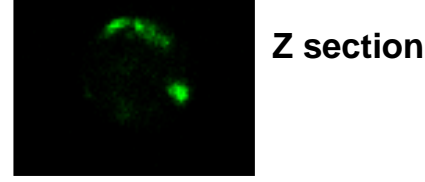

Rit-488

Z section

$+\mathrm{Bf}$
D

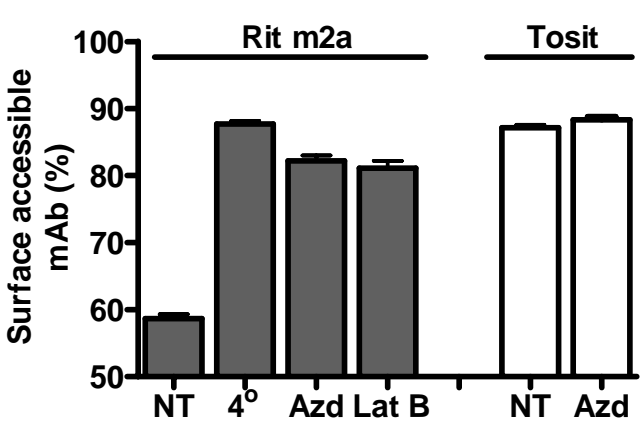

$\mathbf{F}$

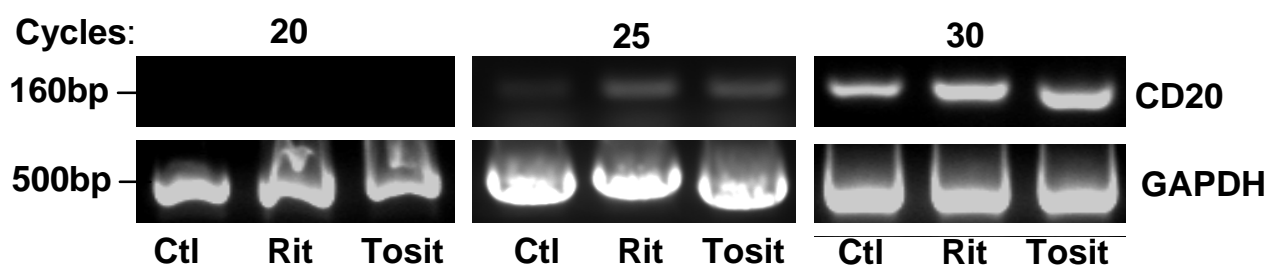

Figure 4. 


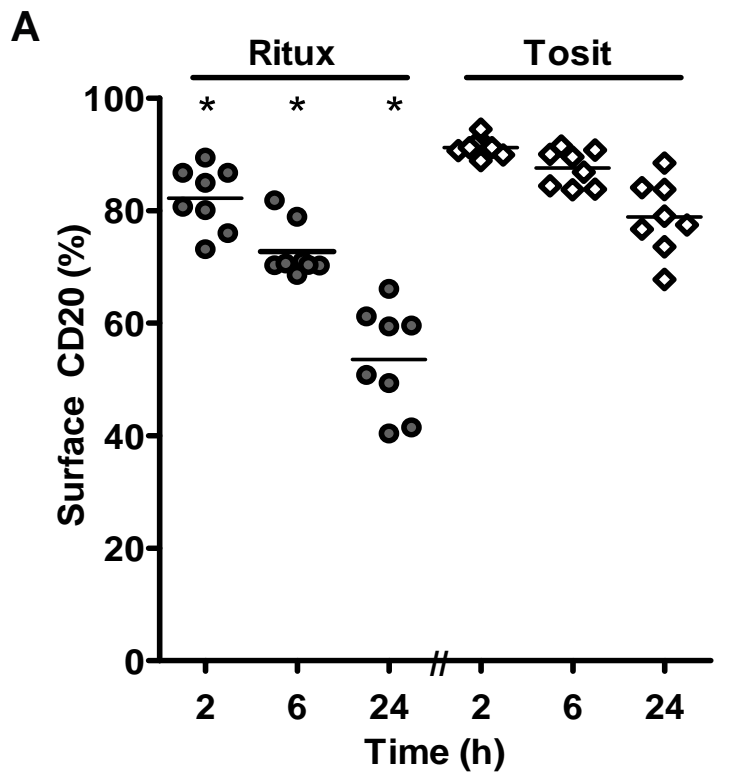

B
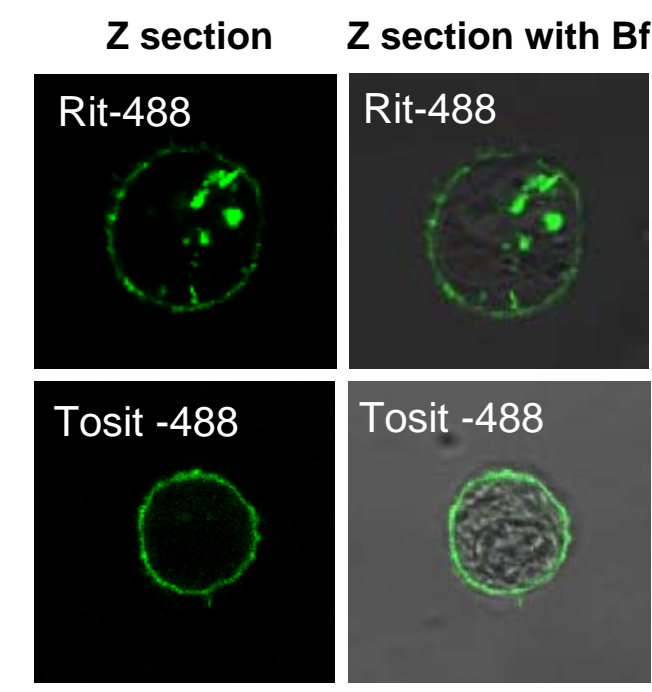

C

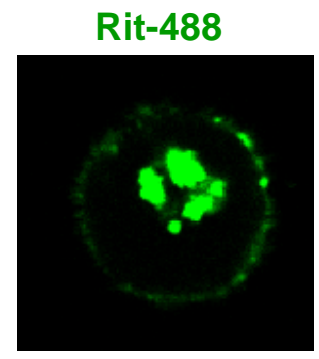

Lyt Red

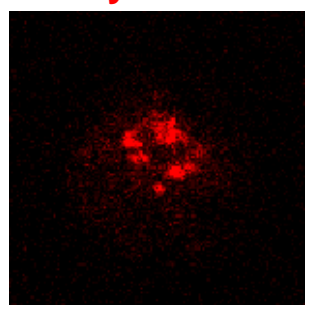

Merge + Bf

Rit-488

Tf-647
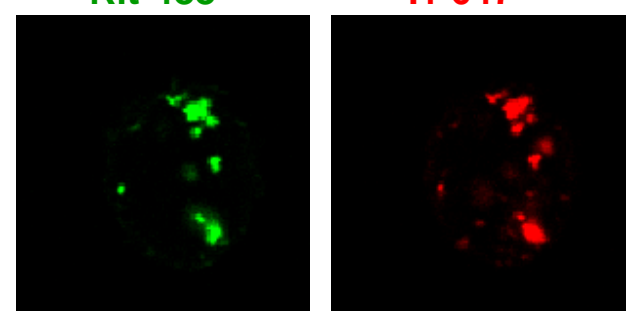

Merge + Bf

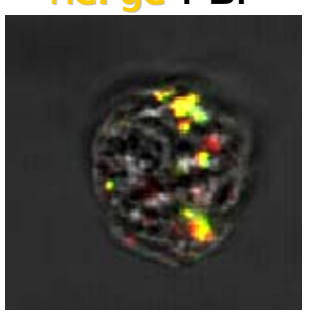

Figure 5. 
A
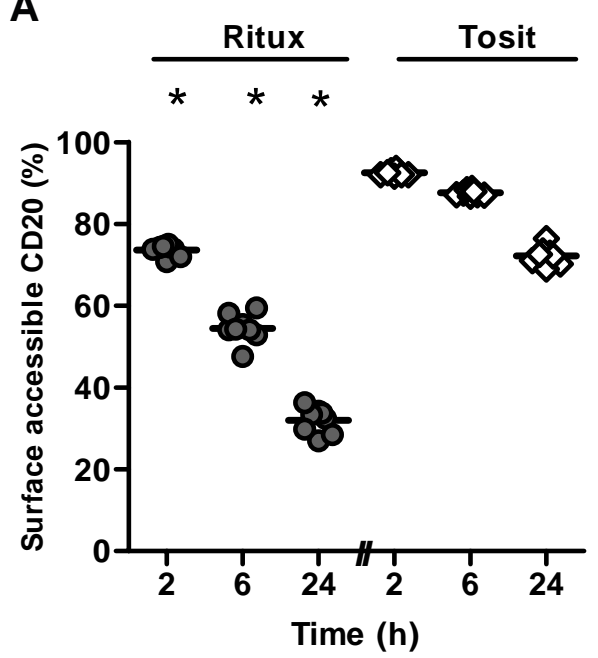

B

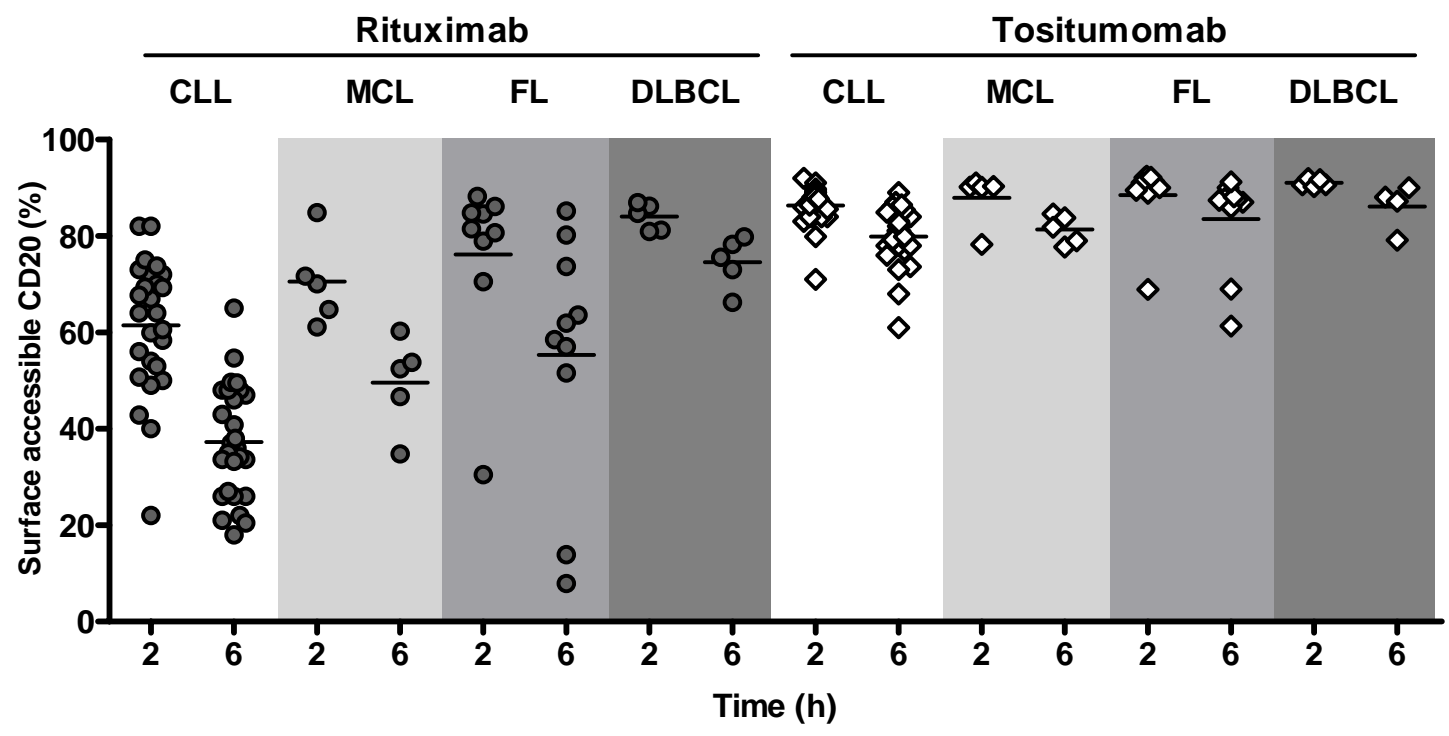

\begin{tabular}{|c|c|c|c|}
\hline \multicolumn{4}{|c|}{$\begin{array}{c}\text { Differences in Rituximab mediated CD20 internalisation } \\
\text { between disease subtypes }\end{array}$} \\
\hline $\begin{array}{c}\text { Time } \\
\text { (h) }\end{array}$ & $\begin{array}{c}\text { CLL v MCL } \\
\text { (P value) }\end{array}$ & $\begin{array}{c}\text { CLL v FL } \\
\text { (P value) }\end{array}$ & $\begin{array}{c}\text { CLL v DLBCL } \\
\text { (P value) }\end{array}$ \\
\hline 2 & ns & 0.015 & 0.0012 \\
\hline 6 & 0.036 & 0.0056 & $<0.0001$ \\
\hline
\end{tabular}

Figure 6. 